NBER WORKING PAPER SERIES

\title{
THE LIMITED MACROECONOMIC EFFECTS OF UNEMPLOYMENT BENEFIT EXTENSIONS
}

Gabriel Chodorow-Reich

Loukas Karabarbounis

Working Paper 22163

http://www.nber.org/papers/w22163

\author{
NATIONAL BUREAU OF ECONOMIC RESEARCH \\ 1050 Massachusetts Avenue \\ Cambridge, MA 02138 \\ April 2016
}

We are grateful to Ellen McGrattan, Emi Nakamura, and participants in seminars and conferences for helpful comments. We thank Claudia Macaluso and Johnny Tang for excellent research assistance, Thomas Stengle of the Department of Labor for help in understanding the unemployment insurance laws, and Bradley Jensen of the Bureau of Labor Statistics for help in understanding the process for constructing state unemployment rates. Karabarbounis thanks the Becker Friedman Institute at the University of Chicago and the Business and Public Policy Faculty Research Fund at Chicago Booth for financial support. The views expressed herein are those of the authors and not necessarily those of the Federal Reserve Bank of Minneapolis, the Federal Reserve System, or the National Bureau of Economic Research.

NBER working papers are circulated for discussion and comment purposes. They have not been peer-reviewed or been subject to the review by the NBER Board of Directors that accompanies official NBER publications.

(C) 2016 by Gabriel Chodorow-Reich and Loukas Karabarbounis. All rights reserved. Short sections of text, not to exceed two paragraphs, may be quoted without explicit permission provided that full credit, including (C) notice, is given to the source. 
The Limited Macroeconomic Effects of Unemployment Benefit Extensions

Gabriel Chodorow-Reich and Loukas Karabarbounis

NBER Working Paper No. 22163

April 2016

JEL No. E24,E62,J64,J65

\begin{abstract}
By how much does an extension of unemployment benefits affect macroeconomic outcomes such as unemployment? Answering this question is challenging because U.S. law extends benefits for states experiencing high unemployment. We use data revisions to decompose the variation in the duration of benefits into the part coming from actual differences in economic conditions and the part coming from measurement error in the real-time data used to determine benefit extensions. Using only the variation coming from measurement error, we find that benefit extensions have a limited influence on state-level macroeconomic outcomes. We use our estimates to quantify the effects of the increase in the duration of benefits during the Great Recession and find that they increased the unemployment rate by at most 0.3 percentage point.
\end{abstract}

Gabriel Chodorow-Reich

Department of Economics

Harvard University

1805 Littauer Center

Cambridge, MA 02138

and NBER

chodorowreich@fas.harvard.edu

Loukas Karabarbounis

University of Chicago

Booth School of Business

5807 S. Woodlawn Avenue

Chicago, IL 60637

and NBER

loukas.karabarbounis@chicagobooth.edu 


\section{Introduction}

Responding to the increase in unemployment during the Great Recession, the potential duration of unemployment insurance (UI) benefits in the United States increased from 26 weeks to up to 99 weeks. Recent studies have found small effects of these benefit extensions on individual outcomes (Rothstein, 2011; Farber and Valletta, 2015). The effect on macroeconomic outcomes has been more controversial. According to one view, by making unemployment relatively more attractive to the jobless, the extension of benefits contributed substantially to the slow recovery of the labor market (Barro, 2010; Mulligan, 2012; Hagedorn, Karahan, Manovskii, and Mitman, 2015). Others have emphasized the potential stimulus effects of increasing transfers to unemployed individuals (Summers, 2010; Congressional Budget Office, 2012; Di Maggio and Kermani, 2015; Kekre, 2016). Distinguishing between these possibilities has important implications for the design of UI policy and for economists' understanding of labor markets.

Quantifying the effects of UI benefit extensions on macroeconomic outcomes is challenging. Federal law links actual benefit extensions in a state directly to state-level macroeconomic conditions. This policy rule mechanically generates a positive correlation between unemployment and benefit extensions, complicating the identification of any direct effect that benefit extensions may have on macroeconomic outcomes.

We combine a novel empirical research design with a standard labor market model augmented with extensions of UI benefits to shed light on this policy debate. Our results are inconsistent with either large negative or positive effects of benefit extensions on macroeconomic aggregates including unemployment, employment, vacancies, and worker earnings. Instead, we find that the extension of benefits has only a limited influence on macroeconomic outcomes.

Our empirical approach starts from the observation that, at the state level, the duration of UI benefits depends on the unemployment rate as estimated in real time. However, realtime data provide a noisy signal of the true economic fundamentals. It follows that two states differ in the duration of their UI benefits because of differences in fundamentals or because of measurement error. We use subsequent revisions of the unemployment rate to separate the 
Table 1: April 2013 Example

\begin{tabular}{llcc}
\hline \hline & & & \\
& & Louisiana & Wisconsin \\
\hline \multirow{2}{*}{ Real-Time Data } & Unemployment Rate (Moving Average) & $5.9 \%$ & $6.9 \%$ \\
& Duration of Benefit Extensions & 14 Weeks & 28 Weeks \\
& Unemployment Rate (Moving Average) & $6.9 \%$ & $6.9 \%$ \\
& Duration of Benefit Extensions & 28 Weeks & 28 Weeks \\
& UI Error & -14 Weeks & 0 Weeks \\
& & & \\
\hline \hline
\end{tabular}

fundamentals from the measurement error. We then use the measurement error component of UI benefit extensions to identify the effects of benefit extensions on state-level macroeconomic aggregates. Effectively, our strategy exploits the randomness in the duration of benefits with respect to economic fundamentals caused by measurement error in the fundamentals.

Table 1 uses the example of Louisiana and Wisconsin in April 2013 to illustrate our strategy. Under the 2008 emergency compensation program, the duration of benefits in a state increased by 14 additional weeks if a moving average of the state's unemployment rate exceeded 6 percent. The unemployment rate measured in real time in Louisiana was 5.9 percent while that in Wisconsin was 6.9 percent, resulting in an additional 14 weeks of potential benefits in Wisconsin relative to Louisiana. However, data revised as of 2015 show that both states actually had the same unemployment rate of 6.9 percent. According to the revised data, both states should have qualified for the additional 14 weeks. We refer to the 14 weeks that Louisiana did not receive as a "UI error." This error reflects mismeasurement of the economic fundamentals rather than differences in fundamentals between the two states and, therefore, provides exogenous variation to estimate the effects of UI benefit extensions on state aggregates. In the event, the actual unemployment rate (from the revised data as of 2015) evolved very similarly following the UI 
error, declining by roughly 0.2 percentage point between April and June 2013 in both states. Our empirical exercise amounts to asking whether this apparent limited influence of extending benefits on unemployment generalizes to a larger sample.

We begin our analysis in Section 2 by discussing relevant institutional details of the UI system, the measurement of real-time and revised unemployment rates, and the UI errors that arise because of differences between real-time and revised data. Similar to the example of Louisiana and Wisconsin in April 2013, during the period 1996-2014 we find more than 600 state-month cases in which the duration of benefits using the revised data differs from the actual duration of benefits. The great majority of these UI errors occur during the Great Recession. This reflects both the additional tiers of benefits duration created by the 2008 emergency compensation program and the fact that most states experienced unemployment rates high enough for measurement errors to affect their eligibility for extended benefits.

Once a UI error occurs, it takes on average nearly 4 months to revert to zero. Workers and firms may adjust their behavior in response to past and current unexpected changes in the UI error and to expectations about the future evolution of the error. We model the UI error as a flexible Markov process and identify its unexpected component, which we call the "UI error innovation." Unlike the error itself, the innovation displays essentially zero serial correlation. Our exercise then proceeds in two steps. First, we estimate the impulse response of state-level variables to a UI error innovation. Then, we use a model matching these impulse responses to show the evolution of macroeconomic aggregates when a negative shock brings the economy into a recession in which agents anticipate extensions of benefits similar to those observed after the Great Recession.

In Section 3 we present our main empirical findings. Innovations in the UI error have negligible effects on state-level unemployment, employment, vacancies, and worker earnings. In our baseline specification, a one-month positive innovation in the UI error generates at most a 0.02 percentage point increase in the unemployment rate. Crucially, a positive UI error innovation raises the fraction of the unemployed who claim UI benefits by a statistically 
significant and an economically reasonable magnitude. Therefore, our results do not reflect the fact that more unemployed do not claim benefits in response to a UI error. They simply reflect the small macroeconomic effects of an increase in UI eligibility and receipt.

We validate our results along three dimensions. First, we show the robustness of our results to the inclusion of a number of controls into the baseline specification, to alternative specifications, and to measurement error in the revised data. Second, we document that lags of variables such as the unemployment rate do not predict UI error innovations. Third, the information content of the UI errors depends on the extent to which the revised unemployment rates measure true economic conditions better than the real-time unemployment rates. Revisions in the unemployment rate reflect better and more source data and methodological developments. We illustrate the improvement in measurement by comparing the predictive power of real-time and revised unemployment rates for actual consumer spending, new building permits issued, and survey attitudes and beliefs. In horse-race regressions, we obtain positive loadings on revised unemployment but not on real-time unemployment, indicating that the revised data better align with agents' decisions and perceptions of economic conditions in real time.

Our empirical estimates provide a direct answer to the question of what would happen if a state increased the duration of unemployment benefits around the neighborhood of a typical UI error, or by about 3 months after a state has already extended benefits by nearly one year. The policy debate following the Great Recession has focused on the different, but related, question of the macroeconomic effects of extending benefits all the way from 26 to as many as 99 weeks. Extrapolating linearly the upper bound of our estimates, we find that extending benefits from 26 to 99 weeks increased the unemployment rate by at most 0.3 percentage point.

In Section 4 we use a model to further illustrate the informativeness of our empirical results for the effects of extending benefits on macroeconomic outcomes. Relative to the direct calculation in the data, the model allows for potential non-linearities in the response of the unemployment rate to benefit extensions and anticipation effects by workers and firms. We augment the standard DMP framework (Diamond, 1982; Mortensen and Pissarides, 1994) with 
a UI policy which determines benefit duration as the sum of two components. The first component is the duration of UI benefits if unemployment were measured without any error. Mimicking the actual UI law, eligible unemployed face an expected duration of benefits that increases in the aggregate unemployment rate. The second component is an exogenous Markov process for the UI error with transition probabilities drawn directly from the data. The remainder of the model deviates minimally from the standard model in the literature in order to make our point as transparent as possible.

The effect of UI policy on macroeconomic outcomes in the DMP model depends crucially on the level of the opportunity cost of employment. We parameterize two model economies. We denote by $z=\xi+b$ the opportunity cost of employment, where $\xi$ is the value of nonmarket work and $b$ is the value of benefits for the average unemployed. The first economy has a high average level of $z=\xi+b=0.81+0.15=0.96$ relative to a marginal product of one, as advocated by Hagedorn and Manovskii (2008). The second economy has a lower average level of $z=\xi+b=0.81+0.06=0.87$. The value of $b=0.06$ accords with the estimates of Chodorow-Reich and Karabarbounis (2015) who show that benefits comprise a small fraction of the average opportunity cost mainly because many unemployed do not receive these benefits.

We begin our theoretical analysis by tracing the model's impulse responses to a one-month UI error innovation. In the high $b$ economy, the unemployment rate increases by roughly 0.15 percentage point, while in the low $b$ economy the unemployment rate increases by less than 0.02 percentage point. The increase in unemployment in both economies reflects the fact that benefit extensions raise the opportunity cost of working for the average unemployed which puts upward pressure on wages, lowers firm profits, and dampens vacancy creation. The difference in magnitude occurs because in the high $b$ economy average firm profits are smaller and, therefore, the increase in the opportunity cost decreases firms profits by more in percent terms. We conclude that the low $b$ model comes much closer than the high $b$ model in matching the empirical response of the unemployment rate to a one-month UI error innovation (less than 0.02 percentage point). 
In the final step of our analysis, we subject both economies to a sequence of large negative shocks that increase unemployment from below 6 percent to roughly 10 percent. Similar to what happened during the Great Recession, the increase in unemployment triggers benefit extensions in the model from 6 months to 20 months. To estimate the influence of benefit extensions on the path of unemployment, we then subject the two economies to the same sequence of shocks but without the benefit extensions. Removing benefit extensions in the high $b$ model reduces the average unemployment rate over a three-year horizon by 3.1 percentage points. The corresponding number in the low $b$ model is less than 0.3 percentage point. Because the low $b$ model matches the response of unemployment to a UI error innovation, we conclude that benefit extensions play a limited role in increasing unemployment during a recession. ${ }^{1}$

Related Literature. The economic literature on the effects of benefit extensions has followed two related lines of inquiry. Motivated in part by a partial equilibrium optimal taxation result linking the optimal provision of UI to individual search behavior (Baily, 1978; Chetty, 2006), a microeconomic literature has studied how various aspects of UI policy affects individual labor supply (see for a survey Krueger and Meyer, 2002). Recent studies in this literature find a small effect of benefit extensions on individual job finding rates and unemployment duration (Rothstein, 2011; Farber and Valletta, 2015). ${ }^{2}$

The macroeconomic effects of UI benefits concern their effect on aggregate unemployment. ${ }^{3}$ Economic theory does not provide a one-to-one mapping between the magnitude of the microeconomic and macroeconomic effects. For example, in a standard DMP model with exogenous job search effort and Nash bargaining, an increase in UI benefits raises workers' outside options, putting an upward pressure on wages and depressing firm vacancy creation. Exogenous search

\footnotetext{
${ }^{1}$ Our conclusion differs from the results of Mitman and Rabinovich (2014) who argue that benefit extensions explain jobless recoveries. Benefit extensions generate significant movements in unemployment only under very high values of opportunity costs $b$ and $z$. The small response of unemployment to a UI error innovation implies that $b$ is much lower than the values generated by the Mitman and Rabinovich (2014) model.

${ }^{2}$ Schmieder, von Wachter, and Bender (2012) and Kroft and Notowidigdo (2015) show that the effect of UI benefit extensions on unemployment duration becomes smaller during recessions. Johnston and Mas (2015) find somewhat larger microeconomic effects than other recent studies.

${ }^{3}$ See Hansen and Imrohoroglu (1992), Krusell, Mukoyama, and Sahin (2010), and Nakajima (2012) for general equilibrium analyses of unemployment insurance policy.
} 
effort implies a zero microeconomic effect, but the decline in total vacancies generates a rise in total unemployment, i.e. a non-zero macroeconomic effect (Hagedorn, Karahan, Manovskii, and Mitman, 2015). Alternatively, in models with job rationing, large microeconomic effects could be consistent with small macroeconomic effects if the job finding rate of UI recipients falls but that of non recipients rises (Levine, 1993; Landais, Michaillat, and Saez, 2015; Lalive, Landais, and Zweimüller, 2015).

In important contributions, Hagedorn, Karahan, Manovskii, and Mitman (2015) and Hagedorn, Manovskii, and Mitman (2015) use a county border discontinuity design to estimate a large positive effect of UI benefit extensions on unemployment. Hall (2013) challenges aspects of their research design and Amaral and Ice (2014) and Coglianese (2015) report that the results are sensitive to changes in the specification. Johnston and Mas (2015) use a sudden change in benefits in Missouri to estimate both the microeconomic and macroeconomic effects. They estimate macroeconomic effects of similar magnitude to the microeconomic effects, but their estimate of the macroeconomic effect depends on a difference-in-difference research design with Missouri the only treated observation. Consistent with our findings, Marinescu (2015) documents a small effect of benefit duration on vacancies. In work closest in approach to our own, Coglianese (2015) also recognizes that measurement error in the unemployment rate may help to identify the macroeconomic effects of duration extensions. Our approach differs from his in using the data revisions to isolate the measurement error in the duration of UI benefits, in explicitly modeling a stochastic process for the measurement error, and in our interpretation of the informativeness of our empirical estimates for key policy experiments through the lens of the DMP model. ${ }^{4}$

\section{Empirical Design}

We begin this section by discussing relevant institutional details of the UI system and the measurement of real-time and revised unemployment rates. We then define the UI errors that

\footnotetext{
${ }^{4}$ Our approach is also related to Suárez Serrato and Wingender (2014) who use data revisions to identify the effects of government spending on state-level outcomes.
} 
arise because of differences between real-time and revised data and discuss how we use these errors to estimate the effects of UI benefit extensions on state-level aggregate outcomes.

\subsection{Unemployment Insurance Laws}

The maximum number of weeks of UI benefits available in the United States varies across states and over time. Regular benefits in most states provide 26 weeks of compensation, with a range between 13 and 30 weeks. The duration of regular UI benefits does not depend on economic conditions in the state. Extended benefits (EB) and emergency compensation provide additional weeks of benefits during periods of high unemployment in a state. The EB program has operated since 1970 and is 50 percent federally funded except for the period 2009-2013 when it became fully federally funded. Emergency compensation programs are authorized and financed on an ad hoc basis by the federal government. Our sample contains the Temporary Emergency Unemployment Compensation (TEUC) program between March 2002 and December 2003 and the Emergency Unemployment Compensation (EUC) program between July 2008 and December 2013. We refer to the combination of EB and emergency compensation as UI benefit extensions.

Qualification for benefit extensions in a state typically depends on the unemployment rate exceeding some threshold. Two measures of unemployment arise in the laws governing these extensions. The insured unemployment rate (IUR) is the ratio of recipients of regular benefits to employees covered by the UI system. The total unemployment rate (TUR) is the ratio of the total number of individuals satisfying the official definition of not working and on layoff or actively searching for work to the total labor force. To avoid very high frequency movements in the available benefit extensions, both the IUR and the TUR enter into the trigger formulas determining extensions as three-month moving averages. A trigger may also contain a lookback provision which requires that the indicator exceed its value during the same set of months in prior years. In Appendix A we list the full set of benefit extension programs, tiers, and triggers in operation during our sample. 


\subsection{Measurement of State Unemployment and Data Revisions}

Whether a state extends its duration of benefits or not depends on state-level estimates of the IUR and TUR as estimated in real time. The real-time IUR uses as inputs administrative data on UI payments and covered employment and, therefore, contains little measurement error. The Local Area Unemployment Statistics (LAUS) program at the Bureau of Labor Statistics (BLS) produces the state-level estimates of the TUR. Unlike the national unemployment rate, which derives directly from counts from the Current Population Survey (CPS) of households, the state unemployment rates incorporate auxiliary information to overcome the problem of small sample sizes at the state level. Better source data and improved statistical models imply substantial revisions in the estimated TUR over time.

We give here a brief description of BLS's procedure to estimate state unemployment rates and present more details in Appendix A. The real-time unemployment rate equals the ratio of real-time unemployment to real-time unemployment plus employment. The BLS uses a state space filter to estimate separately real-time total unemployment and total employment. For unemployment the observed variables are the CPS count of unemployed individuals in the state and the number of insured unemployed. For employment the observed variables are the CPS count of employed individuals and the level of payroll employment in the state from the Current Employment Statistics program. From 2005 to 2014, the procedure also included a real-time benchmarking constraint that allocated pro rata the residual between the sum of filter-based levels across states and the total at the Census division or national level. Finally, in 2009 the BLS began applying a one-sided moving average filter to the state space filtered and benchmarked data.

The BLS publishes revisions of its estimates of the state unemployment rates. The revisions do not determine eligibility into the various extended benefits programs. Revisions occur for three reasons. First, the auxiliary data used in the estimation - insured unemployment and payroll employment - are updated with administrative data not available in real time. Second, the BLS incorporates the entire time series available at the time of the revision into its model, 
replacing the state space filter with a state space smoother and the one-sided moving-average filter with a symmetric filter. Third, the BLS periodically updates its estimation procedure to reflect methodological improvements. Most recently, in 2015 the BLS discontinued the external real-time benchmarking constraint and incorporated a benchmarking constraint within the state space model to reduce the spillover of state-specific noise in the CPS across states.

\subsection{The UI Errors}

We now explain how to construct the UI errors. Let $T_{s, t}$ denote the actual duration of benefit extensions in state $s$ and month $t$, let $\tilde{T}_{s, t}$ denote the hypothetical duration of benefit extensions under the revised data, and let $\hat{T}_{s, t}$ denote the UI error. We define the UI error as the difference between $T_{s, t}$ and $\tilde{T}_{s, t}$ :

$$
T_{s, t}=\tilde{T}_{s, t}+\hat{T}_{s, t} .
$$

Variation in the actual duration of benefit extensions $T_{s, t}$ comes from the component $\tilde{T}_{s, t}$ which depends on the true economic fundamentals and from the component $\hat{T}_{s, t}$ which reflects measurement error in the state unemployment rate. The key idea of our approach is to use variation

induced only from the UI error $\hat{T}_{s, t}$ to identify the effects of benefit extensions on state-level outcomes.

We use the EB program in the state of Vermont to illustrate our measurement of the two components. Figure 1 plots four lines. The blue solid step function shows the additional weeks of benefits available to unemployed in Vermont in each calendar week, $T_{\mathrm{VT}, t}$. This series depends on the real-time unemployment data, plotted by the dashed blue line. The red dashed step function shows $\tilde{T}_{\mathrm{VT}, t}$, the additional weeks of benefits that would have been available in Vermont using the revised unemployment rate series plotted by the dashed red line.

Vermont extended its benefits by an additional 13 weeks in the beginning of 2009. Because the real-time and the revised unemployment rate move closely together in this period, Vermont would have triggered an EB extension using either the real-time or the revised data as an input in the trigger formula. The unemployment rate peaks at the end of 2009. As the unemployment 


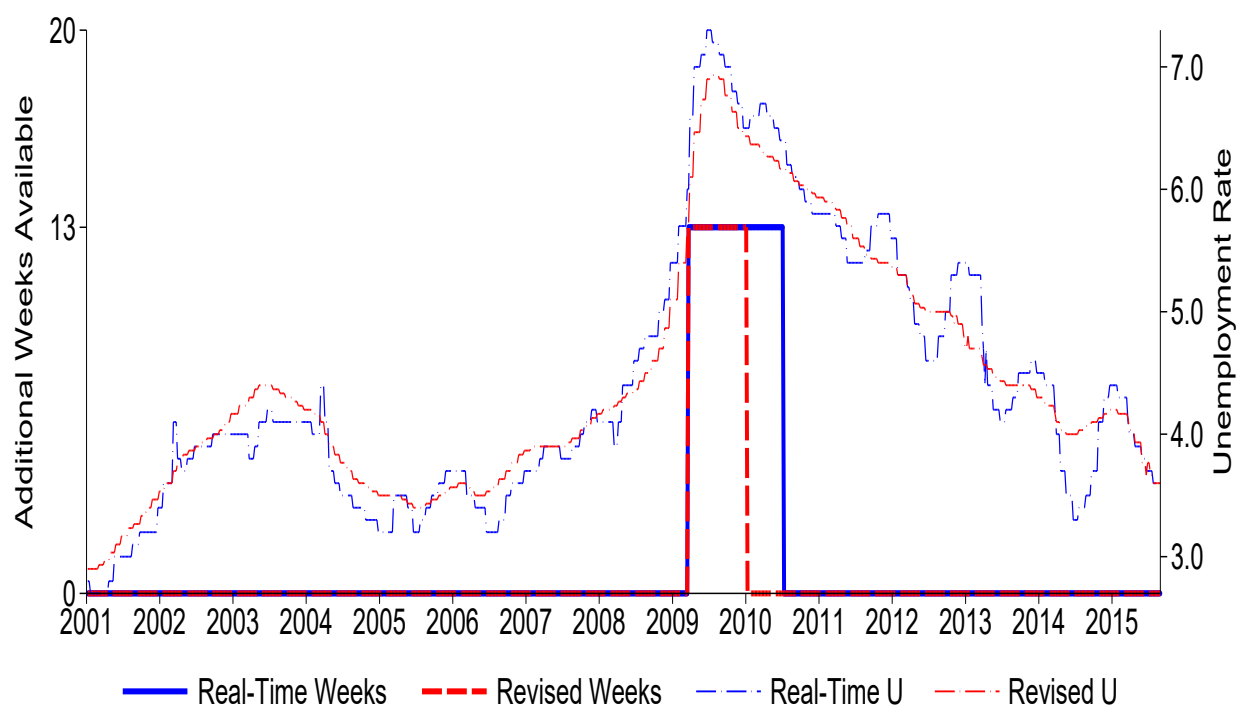

Figure 1: Extended Benefits and Unemployment in Vermont

Notes: The figure plots the duration of benefits $T_{s, t}$ and $\tilde{T}_{s, t}$ (left axis) together with the real-time and revised unemployment rates (right axis).

rate starts to decline, a UI error occurs. In the beginning of 2010, the real-time unemployment rate temporarily increases by a small amount whereas the revised rate continues to decline steadily. Under the revised data, EB should have been discontinued at the beginning of 2010. However, under the real-time data, EB remained in place until roughly the middle of 2010. The UI error, which is the difference between the blue and red step functions, takes the value of 13 weeks during the first part of 2010. This error reflects mismeasurement of Vermont's unemployment rate in real time.

We next describe more formally how we separate $T_{s, t}$ into the component $\tilde{T}_{s, t}$ that corresponds to the fundamentals and the UI error $\hat{T}_{s, t}$. We start with a dataset containing the information in the weekly trigger notices produced by the Department of Labor (DOL). The DOL produces each week a trigger notice that contains for each state the most recent available moving averages of IUR and TUR, the ratios of IUR and TUR relative to previous years, and information on whether a state has any weeks of EB available and whether it has adopted optional triggers for EB status. During periods with emergency compensation programs, the DOL also produces separate trigger notices with the relevant input data and status determination for the emergency programs. We scraped data for EB notices from 2003-2015 and for the EUC 
Table 2: Accuracy of Our Algorithm for Calculating UI Benefit Extensions

\begin{tabular}{lrrrr}
\hline \hline & EB & TEUC02 & EUC08 & Total \\
\hline $\begin{array}{l}\text { Original Trigger Notices } \\
\text { Correctly Imputed }\end{array}$ & 45456 & 3982 & 14291 & \\
Incorrectly Imputed & 44 & 18 & 9 & 71 \\
Corrected Trigger Notices & & & & \\
Correctly Imputed & & & & \\
Incorrectly Imputed & 45494 & 3999 & 14300 & 63793 \\
\hline \hline
\end{tabular}

Notes: The table reports counts of correct or incorrect predictions of UI benefit extensions in our algorithm relative to the outcomes published by the DOL in its trigger notices. The counts are at the state-week level and cover the period 1996-2014. The top panel compares our algorithm to the raw trigger notices. In the bottom panel, we have corrected the information in the raw trigger notices when we find conflicting accounts in either contemporary media sources or in the text of state legislation.

2008 programs from the DOL's online repository. ${ }^{5}$ The TEUC notices are not available online but were provided to us by the DOL. Finally, the DOL library in Washington, D.C. contains print copies of trigger notices before 2003, which we scanned and digitized. ${ }^{6}$ We augment these data with monthly real-time unemployment rates by digitizing archived releases of the monthly state and local unemployment reports from the BLS.

We use the revised unemployment data as of 2015 as inputs into the trigger formulas described in Appendix Table A.1 to calculate $\tilde{T}_{s, t}$. The UI error then equals $\hat{T}_{s, t}=T_{s, t}-\tilde{T}_{s, t} \cdot{ }^{7}$

\footnotetext{
${ }^{5}$ The address is http://www.oui.doleta.gov/unemploy/claims_arch.asp.

${ }^{6}$ The library could not locate notices for part of 1998 . We also digitized notices for the EUC program in operation between 1991 and 1994. However, we found only few non-zero UI errors. We, therefore, exclude this period from our analysis and start in 1996, which is the year in which the BLS began using state space models to construct real-time unemployment for all 50 states.

${ }^{7}$ States have the option to adopt or not two of the triggers for EB status. We follow the actual state laws in determining whether to apply the optional triggers. A complication arises with a temporary change in the law between December 17, 2010 and December 31, 2013. The EB total unemployment rate trigger requires the (three-month) moving average of the unemployment rate in a state to exceed $120 \%$ of its level in the same period in either of the two previous years. With unemployment in many states still high at the end of 2010 but no longer rising, Congress temporarily allowed states to pass laws extending the lookback period by an additional year. Many states passed such laws in the week in which the two-year lookback period would have implied an expiration of EB. When we use the revised unemployment rate to construct the duration of benefits under the EB program, we find that five states would have lost eligibility for EB earlier than in reality. Therefore, in constructing $\tilde{T}_{s, t}$, we assume that states would have adopted the three-year lookback option earlier had the duration of benefits under the EB program followed the revised rather than the real-time unemployment rate. Specifically, we set to zero the UI error from the EB program in any week in which a state had not adopted the three-year lookback trigger, the state did eventually adopt the three-year lookback trigger, and the UI error would have been zero had the state adopted the
} 
To verify the accuracy of our algorithm for constructing $\tilde{T}_{s, t}$, we apply the same algorithm to real-time data for $T_{s, t}$ and compare the duration of extensions implied by our algorithm to the actual duration reported in the trigger notices. Our algorithm does extremely well, as shown in Table 2. Of 63,800 possible state-weeks, we correctly predict the duration in all but 7 cases. $^{8}$

\subsection{Innovations in UI Errors}

The UI error $\hat{T}_{s, t}$ exhibits serial correlation, as shown for example in the Vermont case in Figure 1. This implies that firms and workers respond to past and current unexpected changes in the UI error and to expectations about the future evolution of the error. We define the "UI error innovation" as the current period unexpected component of the UI error:

$$
\epsilon_{s, t}=\hat{T}_{s, t}-\mathbb{E}_{t-1} \hat{T}_{s, t}
$$

where $\mathbb{E}_{t-1} \hat{T}_{s, t}$ denotes the expectation of $\hat{T}_{s, t}$ using information available until period $t-1$.

To identify the unexpected component in the UI error $\epsilon_{s, t}$, we need to estimate the expectation of the future value of the UI error. We aggregate $\hat{T}_{s, t}$ up to a monthly frequency and assume that it follows a first-order discrete Markov chain. Let $\pi_{T}\left(\hat{T}_{s, t}=x_{j} \mid \hat{T}_{s, t-1}=x_{i} ; u_{s, t}, t\right)$ be the probability that $\hat{T}$ transits from a value $x_{i}$ to a value $x_{j}$ conditional on the unemployment rate and calendar time. We allow the probabilities to depend on the unemployment rate and calendar time because the mapping from a measurement error in the unemployment rate to a UI error depends on whether the measurement error occurs in a region of the unemployment rate space sufficiently close to a trigger threshold. For example, in the case of Vermont shown in Figure 1, measurement error in the mid-2000s does not cause a UI error because the unemployment rate is far below the threshold for triggering an extension of benefits. Conditioning on calendar

three-year lookback trigger in that week. This change affects a negligible fraction of observations in our sample (a total of 20 state-week observations).

${ }^{8}$ Our algorithm does better than the trigger notices, in the sense that it identifies more than 50 instances where the trigger notices report an incorrect duration or aspect of UI law which we subsequently correct using contemporary local media sources or by referencing the actual text of state legislation. We suspect but cannot confirm that the remaining discrepancies also reflect mistakes in the trigger notices. A number of previous papers have relied on information contained in the trigger notices (Rothstein, 2011; Hagedorn, Karahan, Manovskii, and Mitman, 2015; Hagedorn, Manovskii, and Mitman, 2015; Marinescu, 2015; Coglianese, 2015). Our investigation reveals that, while small in number, uncorrected mistakes in the trigger notices could induce some attenuation bias. 
time reflects the time variation in UI laws and triggers, for example due to the enactment of an emergency compensation program.

We estimate each probability $\pi_{T}\left(\hat{T}_{s, t}=x_{j} \mid \hat{T}_{s, t-1}=x_{i} ; u_{s, t}, t\right)$ as the fraction of transitions of the UI error from $x_{i}$ to $x_{j}$ for observations in the same unemployment rate and calendar time bin. We form a vector of discrete possible values of $x$ from one-half standard deviation wide bins of $\hat{T}_{s, t}$. Finally, once we have estimated the transition probabilities of the Markov process, we calculate the expectation $\mathbb{E}_{t-1} \hat{T}_{s, t}$ and form the UI error innovation $\epsilon_{s, t}$ using equation (2). ${ }^{9}$

\subsection{Summary Statistics of Variables Used in Analyses}

We draw on a number of sources for state-level outcome variables. From the BLS, along with the (revised) unemployment rate, we use monthly employment growth from the Current Employment Statistics program and monthly labor force participation from the LAUS program. We obtain data on the number of UI claimants across all programs by state and month from the DOL ETA 539 and ETA 5159 activity reports and from special tabulations for the July 2008 to December 2013 period. ${ }^{10}$ We obtain monthly data on vacancies from the Conference Board Help Wanted Print Advertising Index and the Conference Board Help Wanted Online Index. We use the first for the years 1996-2003 and aggregate local areas up to the state level. We use the online index for 2007-2014. The print index continues until June 2008 and the online index begins in 2005. However, the two indexes exhibit conflicting trends between 2004 and 2006 as vacancy posting gradually transitioned from print to online, and we exclude this period from our analysis of vacancies. ${ }^{11}$ Our measure of worker wages, available at quarterly frequency, is the earnings of all and of new workers from the Census Bureau Quarterly Workforce Indicators.

\footnotetext{
${ }^{9}$ An obvious trade-off exists between finer partitioning of the state space and retaining sufficient observations to make the exercise non-trivial. We estimate separate transition matrices for each of the following sequential groupings, motivated by the divisions shown in Table A.1: December 2008 - May 2012 and $5.5 \leq u_{s, t}<7$; December 2008 - May 2012 and $7 \leq u_{s, t}<8.5$; December 2008 - May 2012 and $u_{s, t} \geq 8.5$; June 2012 - December 2013 and $5.5 \leq u_{s, t}<7$; June 2012 - December 2013 and $7 \leq u_{s, t}<9$; June 2012 - December 2013 and $u_{s, t} \geq 9$; January 2002 - December 2003 and $u_{s, t} \geq 5.5 ; u_{s, t} \geq 5.5 ; u_{s, t}<5.5$. We have experimented with coarser groupings and larger bins of $\hat{T}_{s, t}$ with little effect on our results.

${ }^{10}$ These are found at http://www.ows.doleta.gov/unemploy/DataDownloads.asp and http: //workforcesecurity.doleta.gov/unemploy/euc.asp respectively, last accessed February 10, 2016.

${ }^{11}$ The loss of these years has little effect for our results because these years contain very few UI errors. See Sahin, Song, Topa, and Violante (2014) for a description of the vacancy data and a comparison to JOLTS.
} 
Table 3: Summary Statistics of Selected Variables

\begin{tabular}{llrrrrrrr}
\hline \hline \multirow{2}{*}{ Variable } & \multirow{2}{*}{ Symbol } & Mean & \multirow{2}{*}{ S.D. } & \multicolumn{2}{l}{ Within } \\
S.D.
\end{tabular}

Notes: All variables except for Log Earnings are measured at monthly frequency. Denoted variables have been detrended with a state-specific linear time trend. Within S.D. is the standard deviation of the variable's residual from a regression of the variable on state and month fixed effects.

Table 3 reports summary statistics. Our sample covers the period between 1996 and 2014 for the 50 U.S. states. ${ }^{12}$ The average error in the state total unemployment rate, which we denote by $\hat{u}_{s, t}$ and define as the difference between the real-time unemployment rate and the revised unemployment rate, is close to zero with a standard deviation of 0.34 percentage point. Measurement error in the unemployment rate is spread across states and months as its standard deviation changes little after controlling for state and month fixed effects. ${ }^{13}$

A potential concern with our empirical approach is that there are too few or too small errors to identify significant effects of benefit extensions on macroeconomic outcomes. Table 3 shows that this is not true. There are 618 cases in which a state would have had a different duration

\footnotetext{
${ }^{12}$ We exclude months in which a benefit extension program had temporarily lapsed for at least half the month (June 2010, July 2010, and December 2010) and the months immediately following (August 2010 and January 2011).

${ }^{13}$ In contrast to the total unemployment rate, the insured unemployment rate contains almost no revisions. The standard deviation of the error in the insured unemployment rate is only 0.02 percentage point.
} 
of extensions using the revised data. Conditional on a UI error occurring, that is $\hat{T}_{s, t} \neq 0$, the standard deviation of the UI error is larger than 2 months. The interquartile range is roughly 4 months. The fact that there is enough variation in the UI error relative to outcome variables such as the unemployment rate explains the small standard errors of our estimates below.

The average episode of non-zero UI error lasts nearly 4 months and occurs when benefit extensions already provide an additional year of UI eligibility. Most of these episodes occur during the Great Recession. As already discussed in Section 2.4, measurement error in the unemployment rate translates into a UI error only if the state's unemployment rate is sufficiently near a trigger threshold. This fact explains why we examine errors in the number of weeks available $\hat{T}$ directly rather than measurement error in the unemployment rate. It also explains why the UI errors occur mostly in the Great Recession, a period when both the EUC program created additional trigger thresholds and most states had unemployment rates high enough for measurement errors in the unemployment rate to translate into UI errors.

\subsection{Summary of Empirical Design}

Our strategy for overcoming the endogeneity of UI benefit extensions to macroeconomic conditions has the following elements. First, we use data revisions to isolate the component of benefit extensions arising from mismeasurement of state unemployment rates in real time. We denote this component by $\hat{T}_{s, t}$ and find that such UI errors are common and persistent. Next, we construct the unexpected component of the UI error, $\epsilon_{s, t}$. The UI error innovation $\epsilon_{s, t}$ provides variation across states and over time in UI benefit extensions which does not reflect variation in macroeconomic conditions and, as we show below, exhibits essentially zero serial correlation. ${ }^{14}$

We proceed in two steps. In Section 3, we estimate the impulse response of state-level variables to a UI error innovation $\epsilon_{s, t}$ and provide a model-free interpretation of the results. In Section 4, we use a DMP model to show the informativeness of these impulses for macroeconomic

\footnotetext{
${ }^{14}$ Our strategy resembles a Regression Discontinuity (RD) framework, but with the crucial difference being that UI errors reflect larger and more persistent variation than the variation RD uses around a trigger threshold. Using our model, we find that when shocks are very persistent, a pure RD framework could fail to detect significant effects of benefit extensions on unemployment despite the existence of such effects. See Appendix C for more details.
} 
outcomes in response to shocks that trigger extensions of benefits similar to those observed after the Great Recession.

\section{Empirical Results}

We measure the response of labor market variables to a one-month UI error innovation $\epsilon_{s, t}$. Our specification takes the form:

$$
y_{s, t+h}=\beta(h) \epsilon_{s, t}+\Gamma(h) \mathbf{X}_{s, t}+\nu_{s, t+h}
$$

where $y_{s, t+h}$ is an outcome variable in state $s$ and period $t+h, \epsilon_{s, t}$ is the UI error innovation in state $s$ and period $t$, and $\mathbf{X}_{s, t}$ is a vector of covariates. The coefficients $\beta(h)$ for $h=0,1,2, \ldots$ trace out the impulse response function of $y$ with respect to a one-month unexpected change in the UI error. In our baseline specification, $\mathbf{X}_{s, t}$ contains only a state fixed effect $d_{s}$ and a month fixed effect $d_{t}$. We include state and month fixed effects because, as seen in Table 3, they absorb substantial variation in our main outcome variables and, therefore, improve the precision of our estimates. In robustness checks reported below, we either exclude the fixed effects or include additional covariates such as the measurement error in the unemployment rate $\hat{u}_{s, t}$ and lags of the unemployment rate. In all specifications, we cluster standard errors by state and by month.

\subsection{Main Results}

Figure 2 shows impulse responses of the innovation $\epsilon$ and the UI error $\hat{T}$ to a one-month innovation $\epsilon$. As expected, the innovation exhibits essentially no serial correlation. ${ }^{15}$ The UI error $\hat{T}$ rises one-for-one with $\epsilon$ on impact and then decays over the next few months with a half-life of roughly 2 months. In all impulses, dashed lines report the 90 percent confidence interval.

Figure 3 shows an increase in the fraction of the unemployed claiming UI benefits in response to a positive one-month UI error innovation. Upon impact, the fraction of unemployed claiming

\footnotetext{
${ }^{15}$ The lack of serial correlation provides support for our choice of modeling $\hat{T}$ as a first-order Markov process. Time aggregation from weekly to monthly frequency could induce some serial correlation between months $t$ and $t+1$, as an increase in $\hat{T}$ in week 3 or 4 of month $t$ would produce a positive innovation in both $t$ and $t+1$.
} 
Response of $\epsilon$

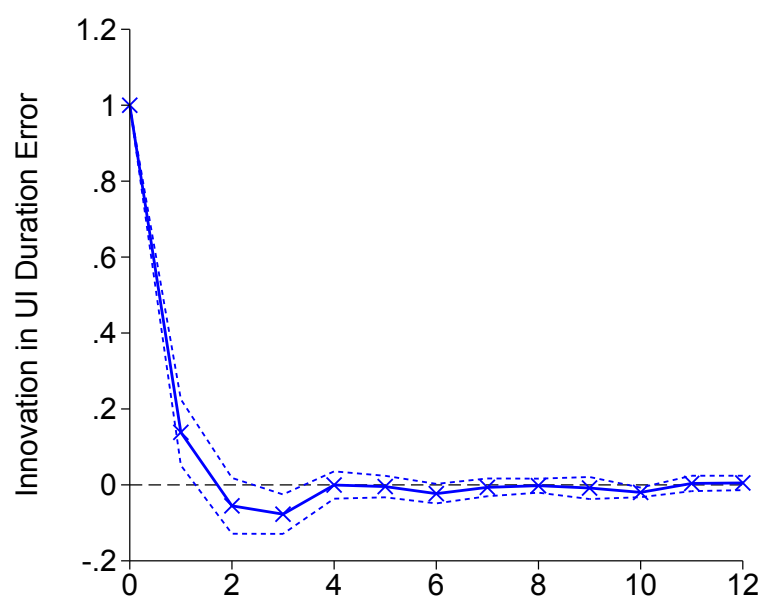

Response of $\hat{T}$

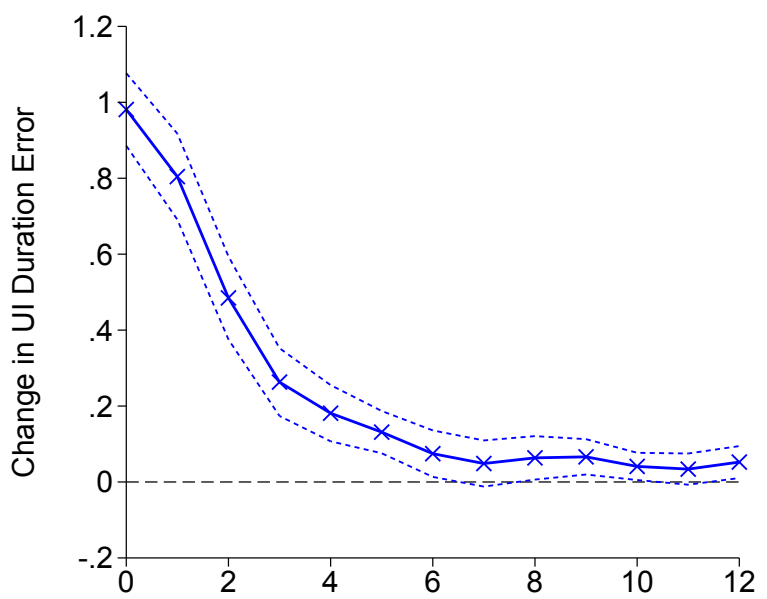

Figure 2: Serial Correlation

Notes: The figure plots the coefficients on $\epsilon_{s, t}$ from the regressions $\epsilon_{s, t+h}=\beta(h) \epsilon_{s, t}+d_{s}(h)+d_{t}(h)+\nu_{s, t+h}$ and $\hat{T}_{s, t+h}=\beta(h) \epsilon_{s, t}+d_{s}(h)+d_{t}(h)+\nu_{s, t+h}$. The dashed lines denote the 90 percent confidence interval based on two-way clustered standard errors.

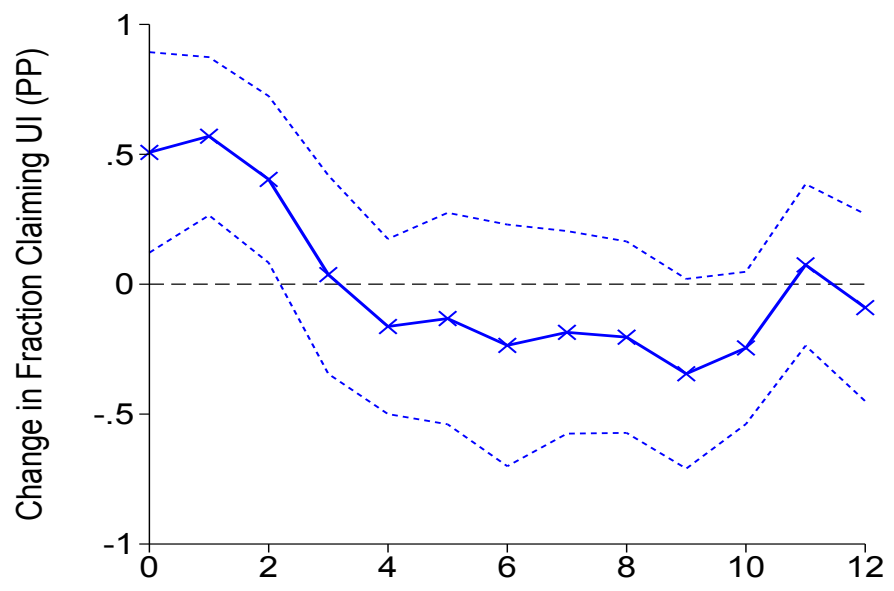

Figure 3: Impulse Response of Fraction Claiming UI

Notes: The figure plots the coefficients on $\epsilon_{s, t}$ from the regression $\phi_{s, t+h}=\beta(h) \epsilon_{s, t}+d_{s}(h)+d_{t}(h)+\nu_{s, t+h}$. The dashed lines denote the 90 percent confidence interval based on two-way clustered standard errors.

UI benefits increases by 0.5 percentage point. The fraction remains high for the next two months and then declines to zero. The innovations in the UI error take place when benefits have, on average, already been extended for roughly 12 months. Using CPS data we estimate that between 0.5 and 1 percent of unemployed would be affected by such an extension, implying a take-up rate in the range of estimates documented by Blank and Card (1991).

Figure 4 shows the main empirical result of the paper. Despite the increase in UI receipt, 


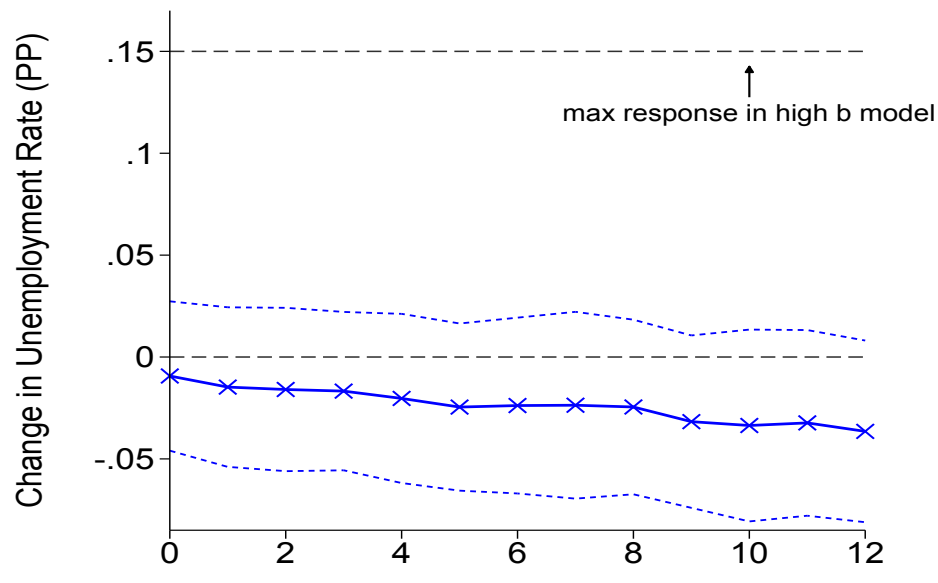

Figure 4: Impulse Response of Unemployment Rate

Notes: The figure plots the coefficients on $\epsilon_{s, t}$ from the regression $u_{s, t+h}=\beta(h) \epsilon_{s, t}+d_{s}(h)+d_{t}(h)+\nu_{s, t+h}$. The dashed lines denote the 90 percent confidence interval based on two-way clustered standard errors.

the (revised) unemployment rate barely responds to the increase in the duration of benefits. Our point estimate for the response of the unemployment rate is slightly negative. The upper bound of our estimate is roughly 0.02 percentage point. The data do not reject a zero response at any horizon up to 12 months. ${ }^{16}$ For comparison, in the same figure we plot a dashed line at 0.15 percentage point. This is the response required for the model of Section 4 to conclude that unemployment in the Great Recession remained persistently high because of an extension of benefits from 6 to 20 months. Our baseline point estimate is more than 6 standard errors below this level.

Figure 5 reports the response of vacancy creation. The economic logic for why the macroeconomic effect of benefit extensions on unemployment may exceed the microeconomic effect is based on a general equilibrium mechanism intermediated by vacancies. The mechanism posits that, following the extension of benefits, firms bargain with unemployed who have higher opportunity cost of working. The result is higher wages and lower firm profits from hiring, discouraging vacancy creation. However, Figure 5 shows that vacancies are unresponsive to a

\footnotetext{
${ }^{16}$ The small standard errors reflect the substantial variation in the right hand side variable $\epsilon$ relative to the outcome variable $u$ shown in Table 3 . To get a back-of-the-envelope estimate of the standard error, consider a bivariate regression with a zero coefficient and no clustering. The standard error of the coefficient would be $\frac{1}{\sqrt{N}} \frac{\sigma_{u}}{\sigma_{\epsilon}}=\frac{1}{\sqrt{11550}} \frac{0.82}{0.33} \approx 0.023$. The two-way clustered standard error reported in Figure 4 differs only slightly from this back-of-the-envelope estimate.
} 


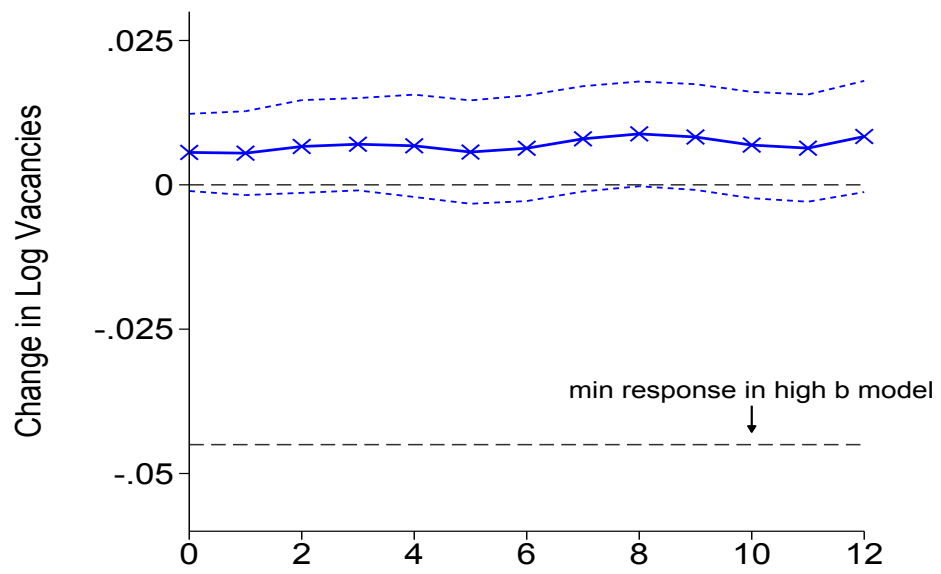

Figure 5: Impulse Response of Log Vacancies

Notes: The figure plots the coefficients on $\epsilon_{s, t}$ from the regression $\log v_{s, t+h}=\beta(h) \epsilon_{s, t}+d_{s}(h)+d_{t}(h)+\nu_{s, t+h}$. The dashed lines denote the 90 percent confidence interval based on two-way clustered standard errors.

UI error innovation. The dashed line plotted at -0.045 denotes the response of log vacancies required to conclude that the extension of benefits from 6 to 20 months caused unemployment in the Great Recession to remain persistently high.

Table 4 summarizes the responses of a number of labor market variables. The left panel reports the point estimates and standard errors at horizons 1 and 4 for the variables already plotted along with employment, labor force participation, and worker earnings. The right panel displays results for a slight modification of equation (3) in which we replace the dependent variable with its difference relative to $t-1, y_{s, t+h}-y_{s, t-1}$. If UI error innovations are uncorrelated with lagged outcome variables, then it would not matter for the point estimates whether we use $y_{s, t+h}$ or $y_{s, t+h}-y_{s, t-1}$ as the dependent variable. We confirm that these correlations are essentially zero in Section 3.3 and, accordingly, obtain similar coefficients in both specifications. For example, in row 1 the response of the unemployment rate is identical up to 3 decimal places. ${ }^{17}$ Across all variables, we find economically negligible responses to a positive one-month innovation in the UI error. The estimated standard errors rule out that the effects are much

\footnotetext{
${ }^{17}$ We prefer the levels specification because of a time-aggregation issue. An increase in $\hat{T}$ in week 4 of month $t-1$ that persists through month $t$ would be associated with an increase in $\epsilon_{s, t}$ and may also be correlated with variables in $t-1$. This implies that the specification in differences attenuates any true effects. The attenuation is likely quite small for a variable such as the unemployment rate which uses as a reference period the week containing the 12th day of the month. However, the attenuation may be larger for a variable such as the fraction of unemployed who claim UI which counts all claims filed during the month.
} 
Table 4: Response of Variables to UI Error Innovation

\begin{tabular}{|c|c|c|c|c|}
\hline \multirow[b]{2}{*}{ Horizon } & \multicolumn{2}{|c|}{ Levels } & \multicolumn{2}{|c|}{ Differences } \\
\hline & 1 & 4 & 1 & 4 \\
\hline 1. Unemployment Rate & $\begin{array}{c}-0.012 \\
(0.023)\end{array}$ & $\begin{array}{c}-0.021 \\
(0.024)\end{array}$ & $\begin{array}{c}-0.012 \\
(0.008)\end{array}$ & $\begin{array}{c}-0.021 \\
(0.014)\end{array}$ \\
\hline 2. Fraction Claiming UI & $\begin{array}{c}0.587^{* *} \\
(0.182)\end{array}$ & $\begin{array}{c}-0.139 \\
(0.199)\end{array}$ & $\begin{array}{c}0.414^{*} \\
(0.162)\end{array}$ & $\begin{array}{c}-0.313 \\
(0.228)\end{array}$ \\
\hline 3. Log Vacancies & $\begin{array}{c}0.006 \\
(0.004)\end{array}$ & $\begin{array}{c}0.006 \\
(0.005)\end{array}$ & $\begin{array}{c}0.001 \\
(0.001)\end{array}$ & $\begin{array}{c}0.002 \\
(0.003)\end{array}$ \\
\hline 4. Log Payroll Employment & $\begin{array}{c}-0.000 \\
(0.000)\end{array}$ & $\begin{array}{c}-0.000 \\
(0.000)\end{array}$ & $\begin{array}{c}0.000 \\
(0.000)\end{array}$ & $\begin{array}{c}0.000 \\
(0.000)\end{array}$ \\
\hline 5. Labor Force Participation Rate & $\begin{array}{c}-0.023 \\
(0.014)\end{array}$ & $\begin{array}{c}-0.017 \\
(0.018)\end{array}$ & $\begin{array}{c}0.008 \\
(0.006)\end{array}$ & $\begin{array}{c}0.014 \\
(0.013)\end{array}$ \\
\hline 6. Log Earnings (All Workers) & $\begin{array}{c}0.001 \\
(0.002)\end{array}$ & $\begin{array}{c}-0.001 \\
(0.002)\end{array}$ & $\begin{array}{c}0.003 \\
(0.004)\end{array}$ & $\begin{array}{c}0.001 \\
(0.003)\end{array}$ \\
\hline 7. Log Earnings (New Hires) & $\begin{array}{c}-0.000 \\
(0.003)\end{array}$ & $\begin{array}{c}0.003 \\
(0.004)\end{array}$ & $\begin{array}{c}0.001 \\
(0.004)\end{array}$ & $\begin{array}{c}0.004 \\
(0.004)\end{array}$ \\
\hline
\end{tabular}

Notes: Each cell reports the result from a separate regression of the dependent variable indicated in the left column on the innovation in the UI error $\epsilon_{s, t}$, controlling for state and period fixed effects. In the panel headlined Levels the dependent variable enters in levels and in the panel headlined Differences it enters with a difference relative to its value in $t-1$. Standard errors clustered by state and time period are shown in parentheses.

larger in magnitude.

Collectively, these results provide direct evidence of the limited macroeconomic effects of increasing the duration of unemployment benefits around the neighborhood of a typical UI error, or by about 3 months after a state has already extended benefits by nearly one year. Extrapolating linearly the upper bound of a 0.02 percentage point increase in the unemployment rate with respect to a one-month UI error innovation, we obtain that moving from 26 to 99 weeks of benefits would increase the unemployment rate by roughly $0.02 \times 17 \approx 0.3$ percentage point. However, this calculation neglects potential non-linear effects of the extension length and the lower persistence of a UI error relative to a policy that increases maximum benefits to 99 weeks as in the Great Recession. In Section 4 we account for these effects within a DMP model and obtain similar results. ${ }^{18}$

\footnotetext{
${ }^{18}$ Non-linearities may arise, for example, because the fraction of unemployed affected by the extension of the duration of benefits declines in the duration of benefits. We have estimated regressions interacting the UI error
} 


\subsection{Robustness}

In this section we investigate the robustness of our main findings. We begin by adding the contemporaneous measurement error in the unemployment rate, $\hat{u}_{s, t}$, to our baseline specification shown in equation (3). Controlling for $\hat{u}_{s, t}$ addresses the concern that subsequent outcome variables $y_{s, t+h}$ may be mechanically correlated with the UI error innovation $\epsilon_{s, t}$ because unemployment rate revisions incorporate the full time series of input data. ${ }^{19}$ In Figure 6 we plot the impulse response of the fraction of unemployed who receive UI (on the left panel) and of the unemployment rate (on the right panel) when we control for the contemporaneous measurement error $\hat{u}_{s, t}$. Similar to our baseline results, we find that a positive one-month UI error innovation increases the fraction of unemployed claiming UI by roughly 0.5 percentage point but that the benefit extension does not result in a significantly higher unemployment rate.

Table 5 more broadly assesses the robustness of our results by adding or removing various controls to the baseline specification. Each entry in the table reports the point estimate and standard error of the coefficient on the UI innovation from a separate regression. We report results for the fraction of unemployed who claim UI, the unemployment rate, and log vacancies, and for horizons of 1 and 4 months.

The first two rows reproduce our baseline results with only state $d_{s}$ and month $d_{t}$ fixed effects, and results when we additionally include the contemporaneous measurement error $\hat{u}_{t, s}$ into the regression. In the third row we report a specification without any controls and without fixed innovation with bins of the duration of benefits $(T<8,8 \leq T<12,12 \leq T<16$, and $T \geq 16)$. As expected, the effect of a UI error innovation on the fraction of unemployed claiming UI is declining in $T_{s, t}$. However, we find little variation in the effect of a UI error innovation on the unemployment rate, with a maximum point estimate below 0.01 .

${ }^{19}$ As described in Section 2.2, real-time unemployment differs from revised unemployment partly because the latter is estimated with a state space smoother using the full time series available at the time of the revision. Thus, lower future unemployment may be associated with a lower revised unemployment rate in period $t$, introducing a negative correlation between the UI error innovation in period $t$ and the future (revised) unemployment rate. The importance of the unemployment path to variation in the measurement error $\hat{u}_{s, t}$ is small; a regression of $\hat{u}_{s, t}$ on 12 leads and lags of the revised unemployment rate finds that they can explain less than 15 percent of the variation in $\hat{u}_{s, t}$. Nonetheless, adding $\hat{u}_{s, t}$ as a control variable in the regression addresses the potential concern directly. The control exploits the fact that the mapping between $\hat{u}_{s, t}$ and $\hat{T}_{s, t}$ is not strictly monotonic. As the example of Vermont in Figure 1 shows, there are instances where substantial measurement error in unemployment $\hat{u}_{s, t}$ does not give rise to a non-zero UI error $\hat{T}_{s, t}$. Inclusion of $\hat{u}_{s, t}$ therefore controls for any "normal" effects of $\hat{u}_{s, t}$ on subsequent outcomes $y_{s, t+h}$ not intermediated through the UI error innovation. 
Response of $\phi$

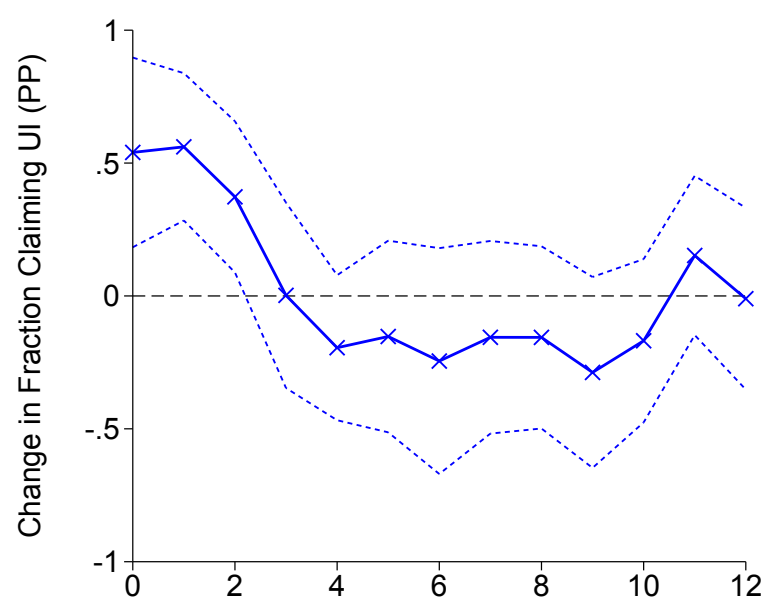

Response of $u$

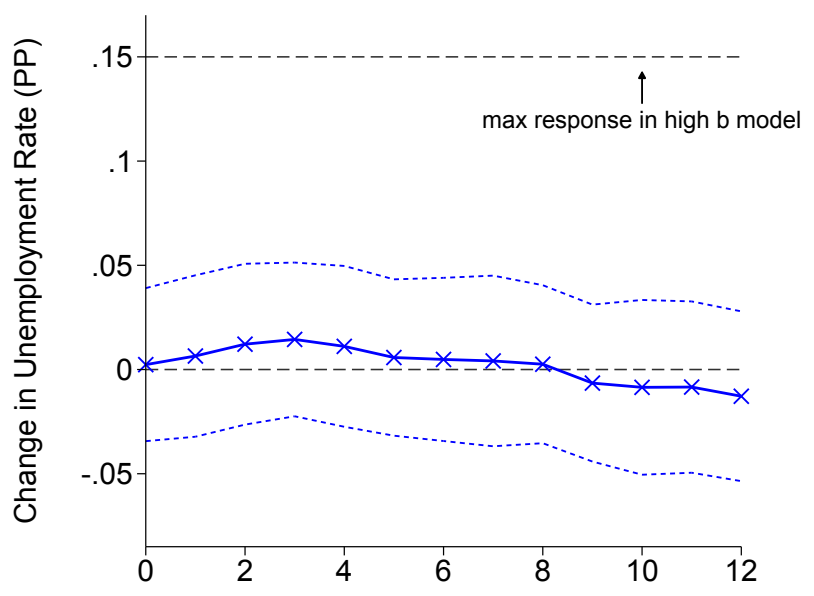

Figure 6: Impulse Responses Controlling for Measurement Error $\hat{u}_{s, t}$

Notes: The figure plots the coefficients on $\epsilon_{s, t}$ from the regressions $\phi_{s, t+h}=\beta(h) \epsilon_{s, t}+d_{s}(h)+d_{t}(h)+\gamma(h) \hat{u}_{s, t}+\nu_{s, t+h}$ and $u_{s, t+h}=\beta(h) \epsilon_{s, t}+d_{s}(h)+d_{t}(h)+\gamma(h) \hat{u}_{s, t}+\nu_{s, t+h}$. The dashed lines denote the 90 percent confidence interval based on two-way clustered standard errors.

effects. Consistent with the UI policy innovation $\epsilon_{s, t}$ not being correlated with any fundamentals, the point estimates from this specification change little relative to the specification that includes fixed effects. However, the standard errors more than double because fixed effects absorb a large fraction of the variation in outcome variables unrelated to the UI error innovation. This explains why we include the state and month fixed effects in our baseline specification.

Rows 4 to 7 control for different functions of the measurement error of the unemployment rate $\hat{u}_{s, t}$. In row 4 we include 12 leads and lags of the measurement error, in row 5 we add a cubic in $\hat{u}_{s, t}$ as a control, in row 6 we allow the effects of $\hat{u}_{s, t}$ to vary depending on its sign, and in row 7 we allow the effects of $\hat{u}_{s, t}$ to vary after 2005 when BLS introduced benchmarking of the local unemployment rates to division or national aggregates. The estimated coefficients do not change significantly in any of these specifications.

In rows 8 and 9 we add to the specification other control variables. In row 8 we include lags of unemployment $u$, the fraction of unemployed who claim benefits $\phi$, and the log of labor productivity $\log p$. Each of these variables enters the state vector in our model of Section 4 . In row 9, we include as a control 12 lags of the unemployment rate. All specifications lead to very similar results to our baseline specification. 
Table 5: Sensitivity of Impulse Responses

\begin{tabular}{|c|c|c|c|c|c|c|}
\hline \multirow{2}{*}{$\begin{array}{l}\text { Dependent Variable } \\
\text { Horizon }\end{array}$} & \multicolumn{2}{|c|}{ Fraction Claiming } & \multicolumn{2}{|c|}{ Unemployment Rate } & \multicolumn{2}{|c|}{ Log Vacancies } \\
\hline & 1 & 4 & 1 & 4 & 1 & 4 \\
\hline 1. $d_{s}, d_{t}$ & $\begin{array}{c}0.587^{* *} \\
(0.182)\end{array}$ & $\begin{array}{c}-0.139 \\
(0.199)\end{array}$ & $\begin{array}{c}-0.012 \\
(0.023)\end{array}$ & $\begin{array}{c}-0.021 \\
(0.024)\end{array}$ & $\begin{array}{c}0.006 \\
(0.004)\end{array}$ & $\begin{array}{c}0.006 \\
(0.005)\end{array}$ \\
\hline 2. $\hat{u}_{s, t}, d_{s}, d_{t}$ & $\begin{array}{l}0.575^{* *} \\
(0.167)\end{array}$ & $\begin{array}{c}-0.167 \\
(0.161)\end{array}$ & $\begin{array}{c}0.009 \\
(0.023)\end{array}$ & $\begin{array}{c}0.010 \\
(0.022)\end{array}$ & $\begin{array}{c}0.003 \\
(0.004)\end{array}$ & $\begin{array}{c}0.003 \\
(0.004)\end{array}$ \\
\hline 3. None & $\begin{array}{c}0.532 \\
(0.553)\end{array}$ & $\begin{array}{c}-0.545 \\
(0.612)\end{array}$ & $\begin{array}{c}-0.002 \\
(0.072)\end{array}$ & $\begin{array}{c}-0.026 \\
(0.072)\end{array}$ & $\begin{array}{r}0.014^{+} \\
(0.008)\end{array}$ & $\begin{array}{r}0.017^{+} \\
(0.010)\end{array}$ \\
\hline 4. $\left\{\hat{u}_{s, t+h}\right\}_{h=-12}^{12}, d_{s}, d_{t}$ & $\begin{array}{l}0.549^{* *} \\
(0.168)\end{array}$ & $\begin{array}{c}-0.199 \\
(0.145)\end{array}$ & $\begin{array}{c}0.006 \\
(0.021)\end{array}$ & $\begin{array}{c}0.009 \\
(0.022)\end{array}$ & $\begin{array}{c}0.004 \\
(0.005)\end{array}$ & $\begin{array}{c}0.004 \\
(0.005)\end{array}$ \\
\hline 5. $\hat{u}_{s, t}, \hat{u}_{s, t}^{2}, \hat{u}_{s, t}^{3}, d_{s}, d_{t}$ & $\begin{array}{c}0.563^{* *} \\
(0.178)\end{array}$ & $\begin{array}{c}-0.183 \\
(0.167)\end{array}$ & $\begin{array}{c}0.020 \\
(0.025)\end{array}$ & $\begin{array}{c}0.019 \\
(0.024)\end{array}$ & $\begin{array}{c}0.003 \\
(0.004)\end{array}$ & $\begin{array}{c}0.003 \\
(0.004)\end{array}$ \\
\hline 6. $\hat{u}_{s, t}, \hat{u}_{s, t} * \mathbb{I}\left\{\hat{u}_{s, t} \geq 0\right\}, d_{s}, d_{t}$ & $\begin{array}{l}0.579^{* *} \\
(0.169)\end{array}$ & $\begin{array}{c}-0.160 \\
(0.165)\end{array}$ & $\begin{array}{c}0.012 \\
(0.025)\end{array}$ & $\begin{array}{c}0.012 \\
(0.023)\end{array}$ & $\begin{array}{c}0.003 \\
(0.004)\end{array}$ & $\begin{array}{c}0.003 \\
(0.004)\end{array}$ \\
\hline 7. $\hat{u}_{s, t}, \hat{u}_{s, t} * \mathbb{I}\{t \geq 2005\}, d_{s}, d_{t}$ & $\begin{array}{l}0.563^{* *} \\
(0.170)\end{array}$ & $\begin{array}{c}-0.161 \\
(0.157)\end{array}$ & $\begin{array}{c}-0.003 \\
(0.024)\end{array}$ & $\begin{array}{c}-0.001 \\
(0.022)\end{array}$ & $\begin{array}{c}0.002 \\
(0.004)\end{array}$ & $\begin{array}{c}0.002 \\
(0.004)\end{array}$ \\
\hline 8. $\hat{u}_{s, t}, u_{s, t-1}, \phi_{s, t-1}, \log p_{s, t-1}, d_{s}, d_{t}$ & $\begin{array}{c}0.412^{* *} \\
(0.139)\end{array}$ & $\begin{array}{c}-0.252 \\
(0.168)\end{array}$ & $\begin{array}{c}0.007 \\
(0.009)\end{array}$ & $\begin{array}{c}0.008 \\
(0.014)\end{array}$ & $\begin{array}{c}0.003 \\
(0.004)\end{array}$ & $\begin{array}{c}0.004 \\
(0.005)\end{array}$ \\
\hline 9. $\hat{u}_{s, t},\left\{u_{s, t-h}\right\}_{h=1}^{12}, d_{s}, d_{t}$ & $\begin{array}{l}0.563^{* *} \\
(0.205)\end{array}$ & $\begin{array}{c}-0.183 \\
(0.174)\end{array}$ & $\begin{array}{l}0.010 \\
(0.008)\end{array}$ & $\begin{array}{l}0.010 \\
(0.014)\end{array}$ & $\begin{array}{c}0.004 \\
(0.003)\end{array}$ & $\begin{array}{c}0.004 \\
(0.004)\end{array}$ \\
\hline
\end{tabular}

Notes: Each cell reports the coefficient from a separate regression of the indicated dependent variable on the UI error innovation $\epsilon_{s, t}$ for the various control variables indicated in each row. Standard errors are clustered by state and time period and are denoted in parentheses.

\subsection{Are UI Error Innovations Predictable?}

We provide further validation of treating the UI error innovations $\epsilon_{s, t}$ as exogenous to the underlying fundamentals by assessing whether they are predicted by lags of outcome variables. The left panel of Table 6 reports (partial) correlations of the innovation in the UI error $\hat{T}_{s, t}$ with the one-month lag of the unemployment rate $u_{s, t-1}$, the fraction of unemployed who claim UI $\phi_{s, t-1}$, and $\log$ vacancies $\log v_{s, t-1}$. In the first column we report the raw correlations, in the second column we report correlations after we partial out state and month fixed effects, and in the third column we report correlations after we partial out state and month fixed effects and the contemporaneous measurement error in the unemployment rate. All correlations are economically small, statistically insignificant, and tightly estimated. 
Table 6: Correlations of Innovations With Lagged Outcome Variables

\begin{tabular}{lccccccc}
\hline \hline \multicolumn{3}{c}{} & \multicolumn{3}{c}{ Innovation in $\hat{T}_{s, t}$} & & \multicolumn{3}{c}{ Innovation in $T_{s, t}$} \\
\cline { 2 - 3 } \cline { 6 - 7 } & None & $d_{s}, d_{t}$ & $\hat{u}_{s, t}, d_{s}, d_{t}$ & & None & $d_{s}, d_{t}$ & $\hat{u}_{s, t}, d_{s}, d_{t}$ \\
\hline \multirow{3}{*}{$u_{s, t-1}$} & 0.005 & -0.000 & 0.000 & & $0.331^{* *}$ & $0.113^{* *}$ & $0.114^{* *}$ \\
& $(0.012)$ & $(0.009)$ & $(0.009)$ & & $(0.067)$ & $(0.032)$ & $(0.032)$ \\
$\phi_{s, t-1}$ & -0.012 & 0.008 & 0.013 & & $0.260^{* *}$ & $0.052^{*}$ & $0.055^{* *}$ \\
& $(0.015)$ & $(0.01)$ & $(0.008)$ & & $(0.047)$ & $(0.018)$ & $(0.018)$ \\
$\log v_{s, t-1}$ & 0.013 & 0.011 & 0.004 & & $-0.186^{* *}$ & -0.030 & $-0.033^{+}$ \\
& $(0.010)$ & $(0.009)$ & $(0.008)$ & & $(0.049)$ & $(0.019)$ & $(0.019)$ \\
& & & & & & & \\
\hline \hline
\end{tabular}

Notes: The table reports the correlation or partial correlation coefficient of the variables in the column and first header row, with the variables partialed out indicated in the second header row.

To set a benchmark for these results, in the right panel of Table 6 we report the same correlations but for the innovation in the actual duration of benefit extensions $T_{s, t}$ rather than the error component $\hat{T}_{s, t}$. Specifically, we repeat the same exercise described in Section 2.4 and construct innovations in the actual duration of benefits $T_{s, t}-\mathbb{E}_{t-1} T_{s, t-1}$. Contrary to the results we obtain when using innovations in the error component of benefit extensions, the innovations in $T_{s, t}$ are predicted by previous outcomes, even after introducing various controls. The sign of the correlations illustrates the identification problem, with a higher unemployment rate predicting a future positive innovation in the duration of UI benefit extensions.

\subsection{Are Revisions Informative About Fundamentals?}

The information content of the revised data matters for our results. If revisions contained little new economic information, then the error component of the benefit duration would be relatively uninformative for estimating the effects of benefit extensions on labor market outcomes. Additionally, even if the revised data better reflect the economy's fundamentals, whether firms and workers respond to these fundamentals or to the data published in real time matters for the interpretation of our results and the policy experiments that we conduct using our model. 
We have already presented two types of evidence consistent with the data revisions containing new information. First, we described the new source data and methodological improvements incorporated in the revisions process. Second, we would not have obtained the economically significant response of the fraction of unemployed claiming benefits to innovations in the UI error if the revised data added only noise to the real-time estimates. We now show that the data revisions contain information for economic choices and beliefs in real time. These results further substantiate the information content of the revisions and provide direct evidence that agents base their decisions on the true economic fundamentals rather than data published in real time.

Our first result pertains to whether the revised or real-time unemployment rate better correlates with actual consumer spending. We estimate a horse-race specification:

$$
y_{s, t}=\beta^{\text {revised }} u_{s, t-2}^{\text {revised }}+\beta^{\text {real-time }} u_{s, t-2}^{\text {real-time }}+\nu_{s, t},
$$

where $y_{s, t}$ denotes either new auto registrations (from R.L. Polk) or new building permits (from the Census Bureau). Both series reflect spending done by a state's residents, derive from actual registration data, and have no mechanical correlation with either the real-time or the revised unemployment rate. We interpret the coefficients $\beta^{\text {revised }}$ and $\beta^{\text {real-time }}$ as the weights one should assign to the revised and real-time unemployment rates as statistical predictors of spending behavior. The unemployment rates enter the regression with a two-month lag to reflect the timing of the release of the LAUS state unemployment data, which usually occurs for month $t-1$ around the 20th day of month $t$. Therefore, agents at the beginning of month $t$ have access to the real-time unemployment rate for month $t-2$ but not for month $t-1$ or $t$. Agents do not know the revised unemployment rate for $t-2$ at the start of month $t$, but may know the economy's true fundamentals. Under the maintained assumption that higher unemployment is associated with lower spending, a finding of $\beta^{\text {revised }}<0$ and $\beta^{\text {real-time }}=0$ provides support for the joint hypothesis that revised data improve the quality of measurement of economic fundamentals and that agents in real time base their decisions on these fundamentals and ignore the measurement error. 
Table 7: Spending Decisions and Unemployment Data

\begin{tabular}{|c|c|c|c|c|c|c|}
\hline & \multicolumn{6}{|c|}{ Dependent Variable } \\
\hline & \multicolumn{3}{|c|}{ Auto Sales } & \multicolumn{3}{|c|}{ Building Permits } \\
\hline & $(1)$ & $(2)$ & $(3)$ & $(4)$ & $(5)$ & $(6)$ \\
\hline Revised $\mathrm{UR}_{s, t-2}$ & $\begin{array}{c}-0.42^{* *} \\
(0.11)\end{array}$ & & $\begin{array}{c}-0.52^{* *} \\
(0.13)\end{array}$ & $\begin{array}{c}-0.09^{* *} \\
(0.02)\end{array}$ & & $\begin{array}{c}-0.10^{* *} \\
(0.02)\end{array}$ \\
\hline Real-time $\mathrm{UR}_{s, t-2}$ & & $\begin{array}{c}-0.34^{* *} \\
(0.10)\end{array}$ & $\begin{array}{c}0.09^{+} \\
(0.05)\end{array}$ & & $\begin{array}{c}-0.07^{* *} \\
(0.02)\end{array}$ & $\begin{array}{c}0.01 \\
(0.02)\end{array}$ \\
\hline State FE & Yes & Yes & Yes & Yes & Yes & Yes \\
\hline Time FE & Yes & Yes & Yes & Yes & Yes & Yes \\
\hline Dep. var. mean & 5.4 & 5.4 & 5.4 & 0.5 & 0.5 & 0.5 \\
\hline Dep. var. sd & 2.0 & 2.0 & 2.0 & 0.4 & 0.4 & 0.4 \\
\hline$R^{2}$ & 0.61 & 0.61 & 0.61 & 0.73 & 0.76 & 0.77 \\
\hline Observations & 10,096 & 9,847 & 9,847 & 15,800 & 12,147 & 12,147 \\
\hline
\end{tabular}

Notes: The dependent variable is indicated in the table header. The auto sales data come from R.L. Polk and correspond to the state of residency of the purchaser. The permits data are for new private housing units and come from the Census Bureau. Standard errors are clustered by state and month and denoted in parentheses.

Table 7 reports the results. Columns 1, 2, 4, and 5 show that both the revised and the real-time unemployment rates are negatively correlated with spending. The key results are shown in columns 3 and 6 in which we introduce jointly both variables in regression (4). For both auto sales and building permits, we estimate $\beta^{\text {revised }}<0$ and $\beta^{\text {real-time }} \approx 0$. The revised unemployment rate contains all the information about spending patterns and, given knowledge of both series, one should put essentially no weight on the real-time data to predict actual spending. ${ }^{20}$

Survey responses from the Michigan Survey of Consumers (MSC) provide further evidence that the revised unemployment data contains significant information. The MSC asks 500 respondents each month a series of questions covering their own financial situation and their views

\footnotetext{
${ }^{20}$ In Appendix B we develop a formula for the attenuation bias that would result in our baseline specification if the revised data do not measure perfectly the true fundamentals. We first show that the more accurate is the revised data in measuring the true fundamentals, the smaller is the potential attenuation bias. We then use the result of Table 7 that the revised data measure true economic fundamentals better than the real-time data to develop a conservative upper bound for the possible attenuation bias. Applying this upper bound to the upper bound of a 0.02 percentage point increase in the unemployment rate in response to a one-month UI error innovation, we take a maximum effect of 0.04 percentage point. This upper bound is still 4.5 standard errors below the 0.15 percentage point response that rationalizes a large effect of benefit extensions on the unemployment rate.
} 
Table 8: Beliefs and Unemployment Data

\begin{tabular}{|c|c|c|c|c|c|c|c|c|c|}
\hline & \multicolumn{9}{|c|}{ Dependent Variable } \\
\hline & AVG & PJOB & PEXP & PINC2 & INEX & DUR & CAR & BUS12 & BUS5 \\
\hline & (1) & $(2)$ & (3) & (4) & $(5)$ & $(6)$ & $(7)$ & $(8)$ & $(9)$ \\
\hline \multirow[t]{2}{*}{ Revised $\mathrm{UR}_{s, t-2}$} & $0.028^{+}$ & $0.663^{*}$ & 0.012 & $-1.086^{*}$ & -0.186 & $0.043^{*}$ & 0.025 & 0.007 & 0.004 \\
\hline & $(0.015)$ & $(0.310)$ & $(0.016)$ & $(0.476)$ & $(0.224)$ & $(0.021)$ & (0.018) & $(0.034)$ & $(0.027)$ \\
\hline \multirow{2}{*}{ Real-time $\mathrm{UR}_{s, t-2}$} & -0.015 & -0.472 & -0.006 & 0.477 & 0.042 & -0.025 & -0.016 & 0.005 & -0.007 \\
\hline & $(0.011)$ & $(0.310)$ & $(0.012)$ & $(0.403)$ & $(0.197)$ & $(0.018)$ & $(0.015)$ & $(0.027)$ & $(0.021)$ \\
\hline State FE & Yes & Yes & Yes & Yes & Yes & Yes & Yes & Yes & Yes \\
\hline Time FE & Yes & Yes & Yes & Yes & Yes & Yes & Yes & Yes & Yes \\
\hline Weighted & Yes & Yes & Yes & Yes & Yes & Yes & Yes & Yes & Yes \\
\hline Individual controls & Yes & Yes & Yes & Yes & Yes & Yes & Yes & Yes & Yes \\
\hline Dep. var. mean & -0.01 & 18.82 & 2.61 & 46.02 & 3.31 & 2.08 & 2.22 & 3.18 & 3.14 \\
\hline Dep. var. sd & 1.00 & 25.16 & 1.31 & 36.95 & 16.50 & 1.73 & 1.81 & 1.92 & 1.79 \\
\hline$R^{2}$ & 0.16 & 0.47 & 0.83 & 0.71 & 0.14 & 0.64 & 0.64 & 0.78 & 0.79 \\
\hline Observations & 82,291 & 81,719 & 80,529 & 70,036 & 79,425 & 78,631 & 78,626 & 75,571 & 79,123 \\
\hline
\end{tabular}

Notes: The dependent variable is indicated in the table header. AVG: simple mean of normalized variables with higher values denoting worse subjective expectations. PJOB: chance will lose job in 5 years. PEXP: personal finances b/w next year (1: Will be better off. 3: Same. 5: Will be worse off). PINC2: percent chance of income increase. INEX: family income expectations 1 year recoded. DUR: durables buying attitudes (1: Good. 3: Pro-con. 5: Bad). CAR: vehicle buying attitudes (1: Good. 3: Pro-con. 5: Bad). BUS12: economy good/bad next year (1: Good times. 2: Good with qualifications. 3: Pro-con. 4: Bad with qualifications. 5: Bad times). BUS5: economy good/bad next 5 years (1: Good times. 2: Good with qualifications. 3: Pro-con. 4: Bad with qualifications. 5: Bad times). Individual controls: sex, marital status, age, $\mathrm{age}^{2}, \mathrm{age}^{3}$, four educational attainment categories, and log income, each interacted with month. Regressions are weighted using survey weights. Standard errors are clustered by state and month and denoted in parentheses.

on the economy. For survey months in or after the year 2000, the Michigan Survey Research Center allowed us to merge external state-level data to anonymized responses. Because sample sizes are too small to aggregate to the state-month level, we instead run our horse-race regression at the individual level and cluster standard errors by state and by month:

$$
y_{i, s, t}=\beta^{\text {revised }} u_{s, t}^{\text {revised }}+\beta^{\text {real-time }} u_{s, t}^{\text {real-time }}+\Gamma \mathbf{X}_{i, s, t}+\nu_{i, s, t} .
$$

Table 8 reports results for a subset of questions in the survey that we expect to correlate with the local unemployment rate. For brevity, we report only specifications with both unemployment rates. Averaging across the eight outcomes we consider, the first column shows that a higher revised unemployment rate is associated with worse subjective perceptions of economic 
Table 9: Effects of Benefit Extensions on Unemployment

\begin{tabular}{lccc}
\hline \hline & Data & \multicolumn{2}{c}{ DMP Models } \\
& High $b$ & Low $b$ \\
\hline Response of $u_{t}$ to $\epsilon_{t}(\max )$ & $<0.02 \mathrm{pp}$ & $0.15 \mathrm{pp}$ & $0.02 \mathrm{pp}$ \\
Effect of extensions on $u_{t}$ during a recession $(3$-year $)$ & $3.1 \mathrm{pp}$ & $0.3 \mathrm{pp}$ \\
\hline \hline
\end{tabular}

conditions. It also shows that, conditional on the revised unemployment rate, the real-time unemployment rate appears to add no information. This result repeats in various individual outcomes as shown in columns 2 to 9 .

\section{DMP Model with UI Benefit Extensions}

In this section we use our empirical results in conjunction with a standard DMP model (Diamond, 1982; Mortensen and Pissarides, 1994) to inform the policy debate on the macroeconomic effects of benefit extensions during the Great Recession. Our empirical estimates suggest a small macroeconomic effect of extending benefits. However, the relationship between unemployment and benefit extensions may be non-linear and depends on expectations of the future path of the extensions. We show how our empirical results discipline a model which accounts for these effects.

Table 9 previews the results and summarizes our logic. In the first step of our argument, we show that an economy parameterized with a low value of benefits $b$ in the opportunity cost of employment matches the small response of unemployment to a one-month UI error innovation (less than 0.02 percentage point). In contrast, in an economy with a high $b$, the response of unemployment to a one-month UI error innovation is almost an order of magnitude larger $(0.15$ percentage point). In the second step of our argument, we subject both economies to a sequence of large negative shocks that increase unemployment and cause benefits to extend from 6 to 
20 months. As the last row of the table shows, removing the benefit extensions lowers the unemployment rate in the low $b$ model by much less than in the high $b$ model. Because only the low $b$ model matches the response of unemployment to a one-month UI error innovation, we conclude that benefit extensions play a limited role in affecting unemployment during a recession.

\subsection{Model Description}

We augment a DMP model with a UI policy to analyze the labor market effects of benefit extensions. The model deviates minimally from the standard model in the literature and shares many features with the models used by Hagedorn, Karahan, Manovskii, and Mitman (2015) and Mitman and Rabinovich (2014) to argue that benefit extensions cause unemployment to remain persistently high following a negative shock. The different conclusion that we reach regarding the role of benefit extensions for macroeconomic outcomes arises because our empirical estimates in Section 3 imply a lower level of the opportunity cost than assumed by these papers.

Labor Market and Eligibility Flows. Each period a measure $u_{t}$ of unemployed search for jobs and a measure $1-u_{t}$ of employed produce output. Unemployed individuals find jobs at a rate $f_{t}$ which is determined in equilibrium. Employed individuals separate from their jobs at an exogenous rate $\delta_{t}$. The law of motion for unemployment is:

$$
u_{t+1}=\left(1-f_{t}\right) u_{t}+\delta_{t}\left(1-u_{t}\right)
$$

Employed individuals who lose their jobs become eligible for UI benefits with probability $\gamma$. There are $u_{t}^{E}$ unemployed who are eligible for and receive UI benefits. Eligible unemployed who do not find jobs lose their eligibility with probability $e_{t}$. The key policy variable in our model is the (expected) duration of benefits $T_{t}$ which equals the inverse of the expiration probability, $T_{t}=1 / e_{t} \cdot{ }^{21}$ Finally, there are $u_{t}-u_{t}^{E}$ ineligible unemployed. Ineligible unemployed who do not find jobs remain ineligible for UI benefits.

\footnotetext{
${ }^{21}$ For expository reasons, in the model $T_{t}$ denotes the total duration of benefits (including the regular benefits), whereas in the data we defined $T_{t}$ as the extension of benefits beyond their regular duration.
} 
We denote by $\omega_{t}=u_{t}^{E} / u_{t}$ the fraction of unemployed who are eligible for and receive UI. This fraction evolves according to the law of motion: ${ }^{22}$

$$
\omega_{t+1}=\frac{\delta_{t} \gamma\left(1-u_{t}\right)}{u_{t+1}}+\left(\frac{u_{t}\left(1-f_{t}\right)\left(1-e_{t}\right)}{u_{t+1}}\right) \omega_{t}
$$

Household Values. All individuals are risk-neutral and discount the future with a factor $\beta$. Employed individuals consume their wage earnings $w_{t}$. The value of an individual who begins period $t$ as employed is given by:

$$
W_{t}=w_{t}+\beta\left(1-\delta_{t}\right) \mathbb{E}_{t} W_{t+1}+\beta \delta_{t}\left(\gamma \mathbb{E}_{t} U_{t+1}^{E}+(1-\gamma) \mathbb{E}_{t} U_{t+1}^{I}\right)
$$

where $U_{t}^{E}$ denotes the value of an eligible unemployed and $U_{t}^{I}$ denotes the value of an ineligible unemployed. These values are given by:

$$
\begin{gathered}
U_{t}^{E}=\xi+B+\beta f_{t} \mathbb{E}_{t} W_{t+1}+\beta\left(1-f_{t}\right)\left(e_{t} \mathbb{E}_{t} U_{t+1}^{I}+\left(1-e_{t}\right) \mathbb{E}_{t} U_{t+1}^{E}\right) \\
U_{t}^{I}=\xi+\beta f_{t} \mathbb{E}_{t} W_{t+1}+\beta\left(1-f_{t}\right) \mathbb{E}_{t} U_{t+1}^{I},
\end{gathered}
$$

where $\xi$ is the value of non-market work and $B$ is the UI benefit per eligible unemployed. ${ }^{23}$ We assume that both $\xi$ and $B$ are constant over time. This allows us to focus entirely on the role of benefit extensions for fluctuations in the opportunity cost of employment. ${ }^{24}$

Surplus and Opportunity Cost of Employment. Firms bargaining with workers over wages cannot discriminate with respect to workers' eligibility status. Therefore, there is a common

\footnotetext{
${ }^{22}$ In the data we have a measure of the fraction of unemployed who claim UI benefits (the variable $\phi$ ) based on administrative data on UI payments. Constructing a high quality panel of take-up rates at the state-month level is not feasible with currently available data. A difference relative to the model of Chodorow-Reich and Karabarbounis (2015) is that, because of this data unavailability, here we do not consider the take-up decision of an unemployed who is eligible for benefits. Therefore, we use interchangeably the terms eligibility for UI benefits and receipt of UI benefits.

${ }^{23}$ Benefit extensions were federally funded between 2009 and 2013 . We think of our model as applying to an individual state during this period and, therefore, we do not impose UI taxes on firms.

${ }^{24}$ In previous work (Chodorow-Reich and Karabarbounis, 2015), we found that the $\xi$ component of the opportunity cost is procyclical. Benefit extensions typically occur when unemployment is high and $\xi$ is low. However, our empirical exercise compares two states with different duration of benefits that have the same economic fundamentals and, therefore, it is appropriate to not control for $\xi$ in our regressions. The constancy of $\xi$ in the model is conservative for our conclusions in this section. Allowing $\xi$ to respond endogenously would lead to an even smaller effect of benefit extensions on unemployment because the decline in $\xi$ would tend to offset the increase in the value of benefits (denoted $b$ below) in the opportunity cost $z=\xi+b$.
} 
wage for all unemployed. This implies that we need to keep track of values and flows for the average unemployed. We define the value of the average unemployed individual as:

$$
U_{t}=\omega_{t} U_{t}^{E}+\left(1-\omega_{t}\right) U_{t}^{I}
$$

The surplus of employment for the average unemployed is given by the difference between the value of working and the value of unemployment. We take:

$$
S_{t}=W_{t}-U_{t}=w_{t}-z_{t}+\beta\left(1-\delta_{t}-f_{t}\right) \mathbb{E}_{t} S_{t+1},
$$

where $z_{t}$ denotes the (flow) opportunity cost of employment for the average unemployed.

The opportunity cost of employment is defined as the flow utility that an unemployed forgoes upon moving to employment. It is given by:

$$
z_{t}=\xi+\underbrace{\omega_{t} B-\left(\delta_{t}\left(\gamma-\omega_{t}\right)+\left(1-f_{t}\right) \omega_{t} e_{t}\right) \beta\left(\mathbb{E}_{t} U_{t+1}^{E}-\mathbb{E}_{t} U_{t+1}^{I}\right)}_{b_{t}},
$$

where $b_{t}$ denotes the benefit component of the opportunity cost of employment. The expression nests the standard model (for instance, Shimer, 2005) that has $b_{t}=B$ if $e_{t}=0$, that is when benefits do not expire, and $\gamma=\omega_{t}=1$, that is when all unemployed are eligible for benefits. More generally, the flow utility loss $b_{t}$ of moving an average unemployed to employment is lower than the benefit $B$. The difference occurs because some unemployed are not eligible for benefits and, even for those unemployed who are eligible, benefits will eventually expire. ${ }^{25}$ Additionally, $b_{t}$ is in general time varying. Extending benefits, which here means a decline in the expiration probability $e_{t}$, increases the fraction of unemployed who are eligible $\omega_{t}$ and raises $b_{t}$ and the opportunity cost of employment $z_{t}$.

Firm Value, Matching, and Bargaining. The value of a firm from matching with a worker is given by:

$$
J_{t}=p_{t}-w_{t}+\beta\left(1-\delta_{t}\right) \mathbb{E}_{t} J_{t+1},
$$

\footnotetext{
${ }^{25}$ The first effect is captured by the first term of $b_{t}$ which is lower than $B$ when $\omega_{t}<1$. The second effect is captured by the second term which is positive because $\gamma>\omega_{t}$ and $\mathbb{E}_{t} U_{t+1}^{E}>\mathbb{E}_{t} U_{t+1}^{I}$.
} 
where $p_{t}$ denotes aggregate labor productivity. There is free entry and, therefore, the expected value of creating a vacancy equals zero:

$$
\frac{\kappa}{q_{t}}=\beta \mathbb{E}_{t} J_{t+1},
$$

where $\kappa$ denotes the upfront cost that an entrant pays to create a vacancy and $q_{t}$ denotes the rate at which vacancies are filled.

Trade in the labor market is facilitated by a constant returns to scale matching technology that converts searching by the unemployed and vacancies by firms into new matches, $m_{t}=$ $M v_{t}^{\eta} u_{t}^{1-\eta}$. We denote by $\eta$ the elasticity of the matching function with respect to vacancies. We define market tightness as $\theta_{t}=v_{t} / u_{t}$. An unemployed matches with a firm at a rate $f_{t}\left(\theta_{t}\right)=m_{t} / u_{t}$ and firms fill vacancies at a rate $q_{t}\left(\theta_{t}\right)=m_{t} / v_{t}=f_{t}\left(\theta_{t}\right) / \theta_{t}$.

Firms and workers split the surplus from an additional match according to the generalized Nash bargaining solution. We denote by $\mu$ the bargaining power of workers. The wage is chosen to maximize the product $S_{t}^{\mu} J_{t}^{1-\mu}$, where $J_{t}$ in equation (14) is a firm's surplus of employing a worker and $S_{t}$ in equation (12) is the surplus that the average unemployed derives from becoming employed. This leads to a standard wage equation:

$$
w_{t}=\mu p_{t}+(1-\mu) z_{t}+\mu \kappa \theta_{t} .
$$

The wage is an increasing function of labor productivity, the opportunity cost, and market tightness.

UI Policy. The duration of UI benefits is given by $T_{t}=\tilde{T}_{t}+\hat{T}_{t}$, where $\tilde{T}_{t}$ denotes the duration of UI benefits in the absence of any measurement error and $\hat{T}_{t}$ is the UI error. Consistent with the results in Section 3.4 that agents respond only to the revised unemployment rate, we assume that firms and workers know the underlying fundamentals (for instance, $u_{t}, p_{t}, w_{t}$ etc.) at the beginning of each period. The statistical agency makes errors in the measurement of the true unemployment rate which result in UI errors $\hat{T}_{t}$. 
The process for $\tilde{T}_{t}$ is:

$$
\tilde{T}_{t}= \begin{cases}\tilde{T}^{1}, & \text { if } 0 \leq u_{t}<\bar{u}^{1} \\ \tilde{T}^{2}, & \text { if } \bar{u}^{1} \leq u_{t}<\bar{u}^{2} \\ \cdots & \\ \tilde{T}^{J}, & \text { if } \bar{u}^{J-1} \leq u_{t}<\bar{u}^{J}=1 .\end{cases}
$$

The UI error follows a first-order Markov process $\pi_{T}\left(\hat{T}_{t} \mid \hat{T}_{t-1} ; u_{t}\right)$. As in the data, the unemployment rate enters into the Markov process to capture the fact that UI errors occur only in particular regions of the state space.

Equilibrium. The state vector of the economy is given by $\mathbf{x}_{t}=\left[u_{t}, \omega_{t}, p_{t}, \delta_{t}, \hat{T}_{t}\right]$. Given exogenous and known processes for $p_{t}, \delta_{t}$, and $\hat{T}_{t}$, an equilibrium of this model consists of functions of the state vector:

$$
\left\{u_{t+1}\left(\mathbf{x}_{t}\right), \omega_{t+1}\left(\mathbf{x}_{t}\right), \theta_{t}\left(\mathbf{x}_{t}\right), W_{t}\left(\mathbf{x}_{t}\right), U_{t}^{E}\left(\mathbf{x}_{t}\right), U_{t}^{I}\left(\mathbf{x}_{t}\right), w_{t}\left(\mathbf{x}_{t}\right), J_{t}\left(\mathbf{x}_{t}\right), b_{t}\left(\mathbf{x}_{t}\right), \tilde{T}_{t}\left(\mathbf{x}_{t}\right)\right\}
$$

such that: (i) The law of motion for unemployment (6) and the law of motion for eligibility (7) are satisfied. (ii) Worker values in equations (8), (9), and (10) are satisfied. (iii) The firm value is given by equation (14) and the free-entry condition (15) holds. (iv) Wages are determined by equation (16), where the opportunity cost of employment is given by equation (13). (v) The duration of UI benefits in the absence of measurement error is given by the schedule (17). Starting from each state vector $\mathbf{x}_{t}$, we have 10 equations to solve for the 10 unknowns. $^{26}$

Effects of UI Policy in the Model. An increase in the current duration of benefits $\left(T_{t}=\right.$ $\left.1 / e_{t}\right)$ affects equilibrium outcomes to the extent that firms and workers expect it to persist in future periods. Combining equations (14) and (15), the decision to create a vacancy in

\footnotetext{
${ }^{26}$ We solve the model globally by iterating on the equilibrium conditions. We begin by guessing functions $\theta^{0}\left(u_{t}, \omega_{t}, p_{t}, \delta_{t}, \hat{T}_{t}\right)$ and $b^{0}\left(u_{t}, \omega_{t}, p_{t}, \delta_{t}, \hat{T}_{t}\right)$ defined over grids of state variables. Given these guesses, we obtain $f($.$) ,$ $\tilde{T}(),. u^{\prime}($.$) and \omega^{\prime}()$, where primes denote next period values, and use equation (16) to obtain the wage function $w($.$) . Next, we iterate on equation (14) to solve for firm value J($.$) . Finally, we use the free-entry condition (15)$ and the definition of the opportunity cost in equation (13) to obtain the implied $\theta^{1}($.$) and b^{1}($.$) functions. We$ update the guesses and repeat until convergence. To evaluate value functions at points $u^{\prime}$ and $\omega^{\prime}$ we use linear interpolation. When solving for the equilibrium policy functions, we impose that the probabilities $f($.$) and q($.$) lie$ between zero and one. These restrictions also guarantee that $v$ and $\theta$ are always positive.
} 
Table 10: Parameter Values

\begin{tabular}{ccccccccccc}
\hline \hline$\beta$ & $\rho$ & $\sigma$ & $\eta$ & $\mu$ & $\delta$ & $\xi$ & $M$ & $\gamma$ & $B$ & $\kappa$ \\
\hline 0.997 & 0.91 & 0.008 & 0.60 & 0.40 & 0.035 & 0.81 & 0.60 & 0.72 & $\{0.26,0.10\}$ & $\{0.05,0.17\}$ \\
\hline \hline
\end{tabular}

the current period depends on the expectation of the present discounted value of firm profits, $\kappa / q_{t}\left(\theta_{t}\right)=\mathbb{E}_{t} \sum_{j=1}^{\infty} \beta^{j}\left(\prod_{i=1}^{j} \frac{\left(1-\delta_{t+i-1}\right)}{\left(1-\delta_{t}\right)}\right)\left(p_{t+j}-w_{t+j}\right)$, where $q_{t}\left(\theta_{t}\right)$ is a decreasing function of current market tightness $\theta_{t}=v_{t} / u_{t}$. By raising the fraction of unemployed who are eligible for UI, an extension of benefits increases future opportunity costs and wages. The increase in wages lowers the expected present value of firm profits and decreases firms' willingness to create vacancies in the current period. The decline in vacancies makes it more difficult for the unemployed to find jobs, which increases the unemployment rate.

\subsection{Parameterization}

A model period corresponds to a month. The schedule for the $\tilde{T}_{t}$ component of UI benefit duration is:

$$
\tilde{T}_{t}= \begin{cases}6, & \text { if } u_{t}<0.065 \\ 9, & \text { if } 0.065 \leq u_{t}<0.08 \\ 12, & \text { if } 0.08 \leq u_{t}<0.09 \\ 20, & \text { if } 0.09 \leq u_{t}\end{cases}
$$

For the UI error component, $\hat{T}_{t}$, we estimate the probabilities $\pi_{T}\left(\hat{T}_{t} \mid \hat{T}_{t-1} ; u_{t}\right)$ in the data separately for each region $u_{t}<0.06,0.06 \leq u_{t}<0.065$, and $0.065 \leq u_{t}$.

Table 10 lists values for other parameters of the model. The discount factor equals $\beta=0.997$. Log productivity follows an $\mathrm{AR}(1)$ process $\log p_{t+1}=\rho \log p_{t}+\sigma \nu_{t}^{p}$, with $\nu_{t}^{p} \sim N(0,1)$, where from the data we estimate that at monthly frequency $\rho=0.91$ and $\sigma=0.008$. The mean separation rate is $\delta=0.035$. We set the elasticity of the matching function with respect to 
vacancies to $\eta=0.60$, worker's bargaining power to $\mu=0.40$, and the value of non-market work to $\xi=0.81$. We then calibrate four parameters, $M, \gamma, B$, and $\kappa$, to hit four targets in the steady state of the model with no benefit extensions (so $T=6$ months). ${ }^{27}$

We parameterize two versions of the model. In the low opportunity cost model we pick $B$ such that $b=0.06$ in the steady state and so $z=\xi+b=0.87$. The value of $b=0.06$ accords with the finding in Chodorow-Reich and Karabarbounis (2015) that benefits comprise a small fraction of the average opportunity $\operatorname{cost}^{28}$ In the high opportunity cost model we pick $B$ such that $b=0.15$ and $z=\xi+b=0.96$. The value of $z=0.96$ was found by Hagedorn and Manovskii (2008) to match the rigidity of wages with respect to productivity.

\subsection{Impulse Responses With Respect to UI Error Innovations}

In Figure 7 we plot the impulse of the unemployment rate with respect to a one-month UI error innovation using simulated data from our model. Following the logic described above, the extension of UI benefits tends to reduce firm profits from filling a vacancy. In the high $b$ model, firm profits are already very small on average because average match surplus - the difference between the marginal product and the opportunity cost of employment - is small. Therefore, the extension of benefits lowers firm's willingness to create vacancies substantially. As the left panel of Figure 7 shows, the maximal response of the unemployment rate is roughly 0.15 percentage point in the high $b$ model. In the low $b$ model depicted in the right panel, the unemployment rate increases by less than 0.02 percentage point. With a low $b$, firm profits are on average higher and the extension of benefits leads to smaller movements in equilibrium vacancies and unemployment.

\footnotetext{
${ }^{27}$ We target $\theta^{T}=1, u^{T}=0.055, \omega^{T}=0.65$, and $b^{T}=\{0.06,0.15\}$. Because we do not consider the takeup decision of the unemployed, $B$ should be understood as the after-tax value of benefits for the average eligible unemployed. This differs from the replacement rate per recipient because of taxes, utility costs of taking up benefits, and a take-up rate below one.

${ }^{28}$ Our calibration is conservative in the sense that reducing the level of $\xi$ would produce even smaller effects of UI policy on aggregate outcomes. Chodorow-Reich and Karabarbounis (2015) show that, with standard preferences, $z$ is between 0.47 and 0.75. Hornstein, Krusell, and Violante (2011) argue that $z$ has to be even smaller in order for models to generate large frictional wage dispersion. Hall and Mueller (2015) also arrive at a small value of $z$ given the large observed dispersion in the value of a job. Costain and Reiter (2008) first pointed out that models with a high level of $z$ generate stronger effects of policies on labor market outcomes than the effects found in cross-country comparisons.
} 


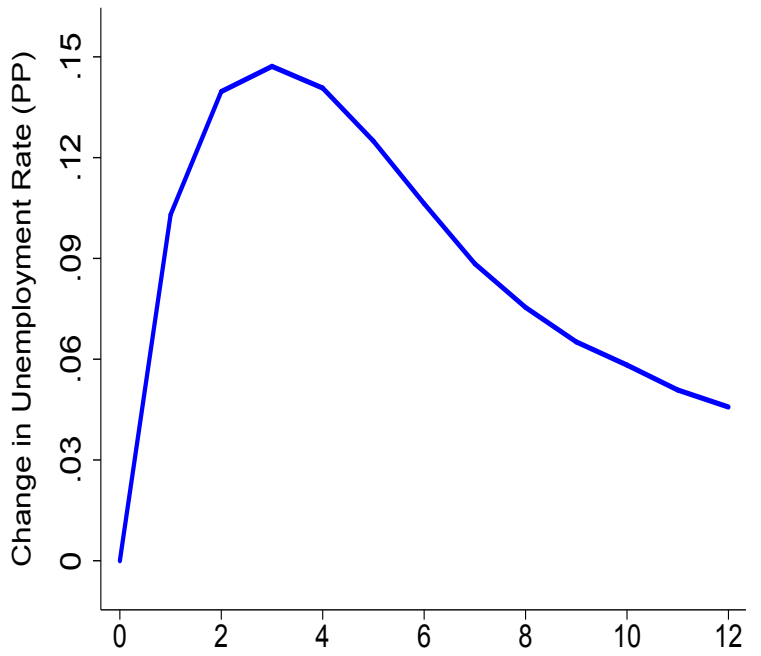

(a) High $b$ Model

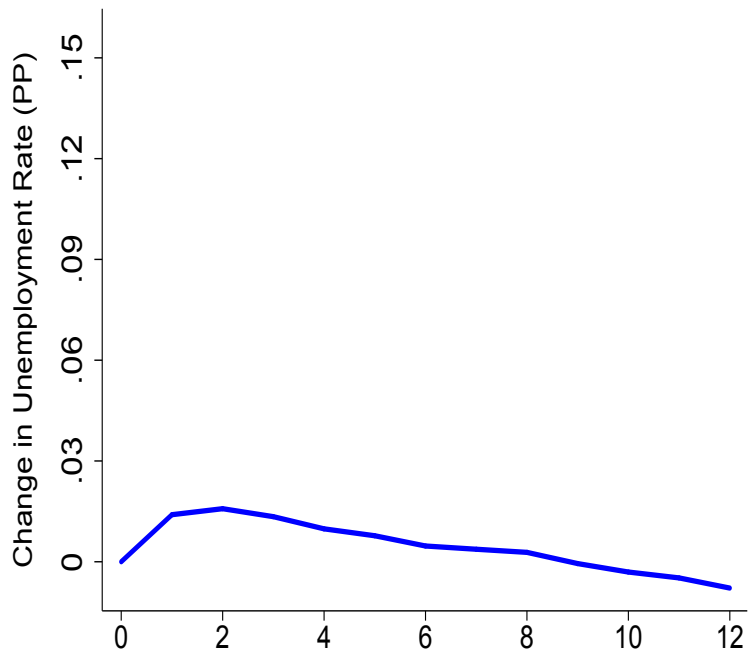

(b) Low $b$ Model

Figure 7: Impulse Response of Unemployment Rate in the Model

Notes: The figure plots the coefficients on $\epsilon_{t}$ from the regression $u_{t+h}=\beta(h) \epsilon_{t}+\nu_{t+h}$ using data generated from model simulations.

In the data, we estimate that the unemployment rate increases by less than 0.02 percentage point when the UI error innovation increases by one month. Therefore, we conclude that the low $b$ model comes much closer than the high $b$ model in matching this response. ${ }^{29}$

\subsection{Effects of Benefit Extensions on Unemployment}

We now examine the effects of a benefit extension that results as a response to a recession rather than to measurement error. Our exercise quantifies the macroeconomic effects of an extension of benefits similar to the policy put in place in the Great Recession. We show that the macroeconomic effects are very different in the low $b$ relative to the high $b$ model.

For this experiment, we shut down all UI errors and set $\hat{T}_{t}=0$ and $T_{t}=\tilde{T}_{t}$ for all periods. We start each of the low $b$ and high $b$ economies in a stochastic steady state in which no shock occurs for a large number of periods. Beginning in month 10, we introduce a sequence of large negative productivity shocks chosen so that unemployment reaches roughly 10 percent in the

\footnotetext{
${ }^{29}$ The difference between the two models does not reflect a failure of the low $b$ model to generate an increase in the fraction of unemployed receiving UI. We actually find that the fraction of eligible unemployed increases by more in the low $b$ model. In Appendix $\mathrm{C}$ we present the impulse responses for the fraction of unemployed receiving UI. We also show impulse responses for the opportunity cost and vacancies.
} 


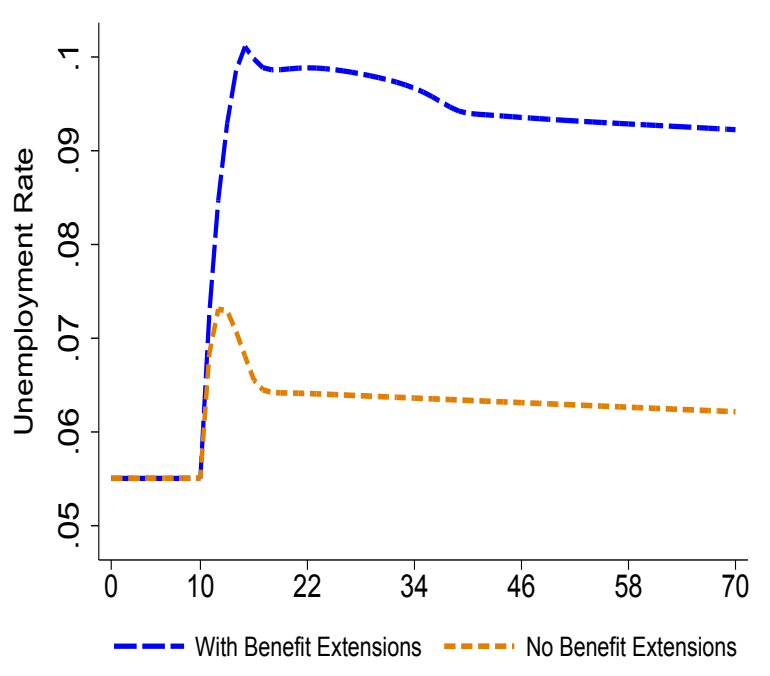

(a) High $b$ Model

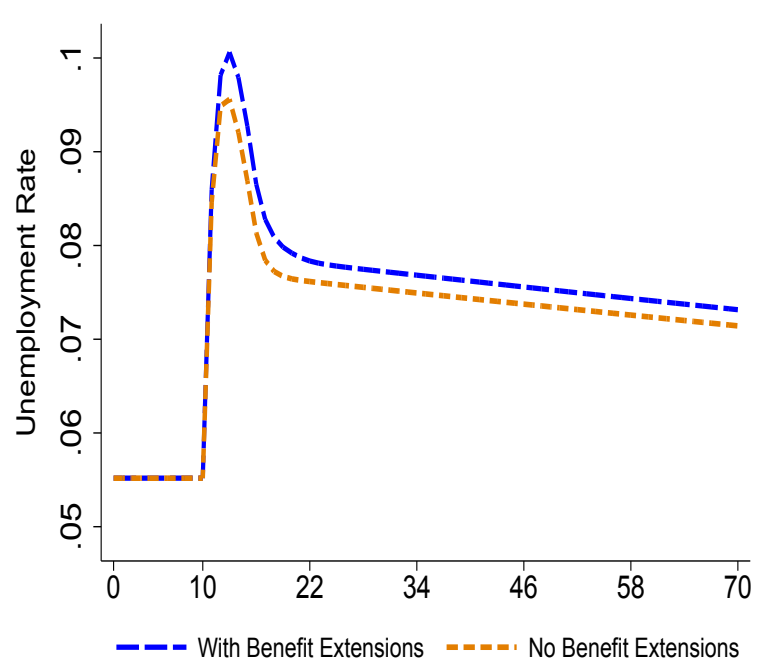

(b) Low $b$ Model

Figure 8: Unemployment Path in the Model

Notes: The figure plots the path of unemployment in response to a sequence of negative shocks with and without benefit extensions in the high $b$ and the low $b$ model.

models with benefit extensions. We depict the path of the shocks in Appendix C. ${ }^{30}$

In the left panel of Figure 8 we plot the paths of unemployment in the high $b$ model under two different UI policy regimes. The upper line shows the path when the duration of benefits rises with unemployment according to the schedule (18). As unemployment rises, the duration of benefits is extended from the initial 6 months to eventually reach 20 months. Unemployment peaks at roughly 10 percent and remains persistently high. In the alternative UI policy regime, the duration of benefits always equals $T_{t}=\tilde{T}_{t}=6$ months. The model without benefit extensions shares the same parameters and is subjected to the same sequence of shocks as the model with benefit extensions. Consistent with the conclusions of Mitman and Rabinovich (2014) and Hagedorn, Karahan, Manovskii, and Mitman (2015), the difference between the two lines shows

\footnotetext{
${ }^{30} \mathrm{~A}$ well-known feature of the DMP model with a low opportunity cost is that it generates unemployment fluctuations of smaller magnitude than observed in the data. Following Shimer (2005), we introduce exogenous separation shocks to generate higher unemployment rates and benefit extensions. To reduce the dimensionality of the state space, we work with a process for the separation rate that depends on productivity, $\delta_{t}=\delta \exp \left(\nu^{\delta}\left(p_{t}-1\right)\right)$. We choose the parameter $\nu^{\delta}$ such that both the high and the low $b$ model generate a maximum unemployment rate of roughly 10 percent in Figure 8. We find $\nu^{\delta}=0$ in the high $b$ model (so we do not need exogenous separation shocks) and $\nu^{\delta}=-10$ in the low $b$ model. In the latter model, $\delta_{t}$ increases from 3.5 to roughly 5.5 percent as productivity declines. We stress that for the arguments in this paper it is not important how we generate high unemployment in the low $b$ model. What is important is that, for some reason, the economy reaches a state where benefits are extended.
} 
the large effect that benefit extensions have on the path of the unemployment rate in the DMP model with a high $b$.

By contrast, the right panel of Figure 8 shows a much smaller effect of benefit extensions on unemployment dynamics. As in the high $b$ model, the duration of benefits increases to 20 months as soon as the unemployment rate exceeds 9 percent. However, the level of the opportunity cost is small on average and, therefore, this extension does not affect significantly the path of the unemployment rate. The average distance between the two unemployment paths is less than 0.3 percentage point. This difference is quite close to our estimates in Section 3 that did not take into account the persistence of benefit extensions or potential non-linearities in the relationship between unemployment and benefit extensions.

\section{Conclusion}

Identifying the effect of UI benefit extensions on macroeconomic outcomes is challenging because benefits are extended in times of elevated unemployment. This simultaneity happens both because U.S. law makes benefit extensions a function of state economic conditions and because policymakers enact emergency compensation in recessions. We use data revisions to decompose variation in the duration of benefits over time and across states into the part coming from actual differences in economic fundamentals and the part coming from measurement error in the realtime data used to determine benefit extensions. Using only the measurement error component for identification, we find an economically reasonable increase in the number of individuals claiming UI, but only a limited influence of benefit extensions on key state-level macroeconomic outcomes including unemployment, employment, vacancies, and wages.

Viewed through the lens of a standard DMP model, this small response is consistent with a low opportunity cost of giving up benefits for the average unemployed. A low opportunity cost means that even large extensions of benefits have limited influence on labor market variables in the model. Together, our empirical and theoretical results imply that the unprecedented increase of benefits during the Great Recession contributed at most 0.3 percentage point to the 
increase in the unemployment rate.

While our results speak directly to the public policy debate over the macroeconomic effects of benefit extensions, economic channels beyond a low opportunity cost of benefits could play a role. These channels include an offsetting stimulus effect from transferring resources to unemployed individuals with high marginal propensity to consume, labor market spillovers as lower search effort by UI recipients raises job finding rates for non-recipients, and wage determination mechanisms that do not depend on the opportunity cost of employment. Quantifying each of these channels separately would be a valuable step for future research.

The most basic function of UI is to provide income replacement for individuals who have lost their jobs. The value of this insurance mechanism may increase in the duration of an unemployment spell as individuals draw down on their assets and other sources of income. The results in this paper do not speak to this income support function nor to the value of increasing insurance during recessions when the typical duration of unemployment spells rises. Our results simply suggest that concerns about large negative macroeconomic effects of UI are not warranted.

\section{References}

Amaral, P., And J. Ice (2014): "Reassessing the Effects of Extending Unemployment Insurance Benefits," Federal Reserve Bank of Cleveland, Economic Commentary.

BAILY, N. (1978): "Some Aspects of Optimal Unemployment Insurance," Journal of Public Economics, 10, 379-402.

Barro, R. (2010): "The Folly of Subsidizing Unemployment," The Wall Street Journal, August 30.

Blank, R., and D. CARD (1991): "Recent Trends in Insured and Uninsured Unemployment: Is There an Explanation?," Quarterly Journal of Economics, 106(4), 1157-89.

Bureau of Labor Statistics (2014): "Report on Revision to State and Area Time-Series Models," Technical Report. 
Chetтy, R. (2006): "A General Formula for the Optimal Level of Social Insurance," Journal of Public Economics, 90(10-11), 1879-901.

Chodorow-Reich, G., and L. Karabarbounis (2015): "The Cyclicality of the Opportunity Cost of Employment," Journal of Political Economy, Forthcoming.

Coglianese, J. (2015): "Do Unemployment Insurance Extensions Reduce Employment?," Harvard University Working Paper.

Congressional Budget Office (2012): "Unemployment Insurance in the Wake of the Recent Recession," Technical Report.

Costain, J., And M. Reiter (2008): "Business Cycles, Unemployment Insurance, and the Calibration of Matching Models," Journal of Economic Dynamics and Control, 32, 1120-55.

Department of Labor (2015): Chronology of Federal Unemployment Compensation Laws.

Di Maggio, M., And A. Kermani (2015): "The Importance of Unemployment Insurance as an Automatic Stabilizer," Columbia Business School Research Paper No. 15-31.

Diamond, P. (1982): "Wage Determination and Efficiency in Search Equilibrium," Review of Economic Studies, 49(2), 217-27.

Farber, H., and R. Valletta (2015): "Do Extended Unemployment Benefits Lengthen Unemployment Spells? Evidence from Recent Cycles in the U.S. Labor Market," Journal of Human Resources, 50(4), 873-909.

Hagedorn, M., F. Karahan, I. Manovskit, and K. Mitman (2015): "Unemployment Benefits and Unemployment in the Great Recession: The Role of Macro Effects," NBER Working Paper No. 19499.

Hagedorn, M., and I. Manovski (2008): "The Cyclical Behavior of Equilibrium Unemployment and Vacancies Revisited," American Economic Review, 98(4), 1692-706.

Hagedorn, M., I. ManovskiI, and K. Mitman (2015): "The Impact of Unemployment Benefit Extensions on Employment: The 2014 Employment Miracle?," NBER Working Paper No. 20884.

Hall, R. (2013): "Some Observations on Hagedorn, Karahan, Manovskii, and Mitman," Stanford University Working Paper. 
Hall, R., And A. Mueller (2015): "Wage Dispersion and Search Behavior," Stanford University Working Paper.

Hansen, G., And A. Imrohoroglu (1992): "The Role of Unemployment Insurance in an Economy with Liquidity Constraints and Moral Hazard," Journal of Political Economy, 100(1), 118-42.

Hornstein, A., P. Krusell, and G. Violante (2011): "Frictional Wage Dispersion in Search Models: A Quantitative Assessment," American Economic Review, 101(7), 2873-98.

Johnston, A., And A. Mas (2015): "Potential Unemployment Insurance Duration and Labor Supply: The Individual and Market-level Response to a Benefit Cut," Princeton University Working Paper.

KeKRe, R. (2016): "Unemployment Insurance in Macroeconomic Stabilization," Harvard University Working Paper.

Kroft, K., And M. Notowidigdo (2015): "Should Unemployment Insurance Vary With the Unemployment Rate? Theory and Evidence," Review of Economic Studies, Forthcoming.

Krueger, A., And B. Meyer (2002): "Labor Supply Effects of Social Insurance," in Handbook of Public Economics, ed. by A. Auerbach, and M. Feldstein, pp. 2327-92. Elsevier.

Krusell, P., T. Mukoyama, and A. Sahin (2010): "Labour-Market Matching with Precautionary Savings and Aggregate Fluctuations," Review of Economic Studies, 77(4), 1477-507.

Lalive, R., C. Landais, and J. Zweimüller (2015): "Market Externalities of Large Unemployment Insurance Extension Programs," American Economic Review, 105(12), 3564-96.

Landais, C., P. Michaillat, and E. Saez (2015): "A Macroeconomic Approach to Optimal Unemployment Insurance: Theory," University of California at Berkeley Working Paper.

Levine, P. B. (1993): "Spillover Effects Between the Insured and Uninsured Unemployed," Industrial and Labor Relations Review, 47(1), 73-86.

Marinescu, I. (2015): "The General Equilibrium Impacts of Unemployment Insurance: Evidence from a Large Online Job Board," University of Chicago Working Paper.

Mitman, K., and S. Rabinovich (2014): "Do Unemployment Benefit Extensions Explain the Emergence of Jobless Recoveries?," Stockholm University Working Paper. 
Mortensen, D., And C. Pissarides (1994): "Job Creation and Job Destruction in the Theory of Unemployment," Review of Economic Studies, 61(3), 397-415.

Mulligan, C. (2012): The Redistribution Recession. Oxford University Press.

NAKAJima, M. (2012): "A Quantitative Analysis of Unemployment Benefit Extensions," Journal of Monetary Economics, 59, 686-702.

Pfeffermann, D., and R. Tiller (1996): "Small-Area Estimation with State-Space Models Subject to Benchmark Constraints," Journal of the American Statistical Association, 101(476), 1387-97.

Rothstein, J. (2011): "Unemployment Insurance and Job Search in the Great Recession," Brookings Papers on Economic Activity, 143-214.

Sahin, A., J. Song, G. Topa, and G. L. Violante (2014): "Mismatch Unemployment," American Economic Review, 104(11), 3529-64.

Schmieder, J., T. von Wachter, and S. Bender (2012): "The Effects of Extended Unemployment Insurance Over the Business Cycle: Evidence from Regression Discontinuity Estimates over Twenty Years," Quarterly Journal of Economics, 127(2), 701-52.

Shimer, R. (2005): "The Cyclical Behavior of Equilibrium Unemployment and Vacancies," American Economic Review, 95(1), 25-49.

SuÁrez Serrato, J., And P. Wingender (2014): "Estimating Local Fiscal Multipliers," Duke University Working Paper.

Summers, L. (2010): "The Economic Case for Extending Unemployment Insurance," The White House Blog, July 14.

Tiller, R. (1992): "Time Series Modeling of Sample Survey Data from the U.S. Current Population Survey," Journal of Official Statistics, 8(2), 149-66. 


\title{
The Limited Macroeconomic Effects of Unemployment Benefit Extensions
}

\author{
Online Appendix \\ Gabriel Chodorow-Reich Loukas Karabarbounis
}

April 2016

\section{A Data Appendix}

In this data appendix we describe the extended benefits programs and the BLS methodology to estimate the state unemployment rates.

\section{A.1 Extended Benefits and Emergency Compensation Programs}

In Table A.1 we list the full set of benefit extension programs, tiers, and triggers in operation during our sample.

\section{A.2 State Unemployment Rate Estimation Methodology}

We outline the BLS methodology for estimating the state unemployment rates. The BLS first introduced state space models in 1989 and began to apply these models to all states in 1996. Bureau of Labor Statistics (2014) provides an in-depth but non-technical overview of what follows and Tiller (1992) and Pfeffermann and Tiller (1996) provide a more technical treatment.

The first step of the real-time estimation involves estimating the state space models separately for total unemployment and employment. The unemployment rate is constructed from these two estimates. Let $y_{s, t}+o_{s, t}$ denote the direct count of a variable such as state employment or unemployment from the CPS, where $o_{s, t}$ denotes any outlier component identified using intervention model methods. For each state, the observation equation is:

$$
y_{s, t}=\alpha_{s, t} x_{s, t}+L_{s, t}+S_{s, t}+I_{s, t}+e_{s, t},
$$


where $x_{s, t}$ is an external regressor (insured unemployment for unemployment and CES payroll employment for employment), $L_{s, t}$ is a trend level, $S_{s, t}$ is a seasonal component, $I_{s, t}$ is an "irregular" component, and $e_{s, t}$ is the observation error. The state space model employment or unemployment is $Y_{s, t}=\alpha_{s, t} x_{s, t}+L_{s, t}+S_{s, t}+I_{s, t}=y_{s, t}-e_{s, t}$.

The model state equations are:

$$
\begin{aligned}
\alpha_{s, t} & =\alpha_{s, t-1}+\eta_{\alpha, s, t}, \\
L_{s, t} & =L_{s, t-1}+R_{s, t}+\eta_{L, s, t}, \\
R_{s, t} & =R_{s, t-1}+\eta_{R, s, t}, \\
S_{s, t} & =\sum_{j=1}^{6} S_{j, s, t},
\end{aligned}
$$

where $I_{s, t}, \eta_{\alpha, s, t}, \eta_{L, s, t}$, and $\eta_{R, s, t}$ are independent normal random variables, and $S_{j, s, t}$ are seasonal frequency functions. A generalized Kalman filter estimates the system. ${ }^{1}$

BLS introduced a major update in 2005 with the incorporation of real-time benchmarking to Census Division and national totals. Each month, after estimation of the state space system, BLS would allocate the residual between the sum of model estimates of not seasonally adjusted series for Census Divisions $\left(L_{t}+I_{t}\right)$ and the national CPS total pro rata to each division, and then repeat the process for states within a division. ${ }^{2}$ In that way, the real-time sum of state employment and unemployment would always equal the national total. However, the pro rata allocation meant that state-specific residuals would "spillover" to neighboring states. In 2009, BLS began applying a one-sided moving average Henderson filter to the benchmarked series.

The most recent major update to the real-time model occurred in 2015 and involves incorporating the real-time benchmarking directly into the state space filter. The observation vector is augmented to include the difference between the sum of not seasonally adjusted model state unemployment and employment levels and their Census Division direct estimate (excluding

\footnotetext{
${ }^{1}$ Because of the rotating panel structure of the CPS sample, the observation equation errors may be serially correlated. The generalized Kalman filter uses GLS instead of OLS to find the conditional mean of the state vector given the updated observation vector. In addition, BLS first fits an $\operatorname{AR}(15)$ model to estimate the $\alpha_{s, t}$ vector.

${ }^{2}$ At the Census Division level the state space estimation excludes the external regressors insured unemployment or payroll employment. In terms of equations (A.1) to (A.5), $\alpha_{c d, t}=0$ and $\operatorname{var}\left(\eta_{c d, t}\right)=0$.
} 
identified outliers), and the estimation constrains the variance of the innovation in this component to be zero. Outlier components $o_{s, t}$ are subsequently added back to the states from which they originated. The incorporation of the benchmarking within the filter substantially mitigates spillovers of unusual residuals across states within a division.

\section{B Measurement Error in the Revised Data}

In this appendix we examine the case in which the revised data measure the fundamentals with some error. Measurement error in the revised data introduces an attenuation bias in our estimated impulse responses. We derive an upper bound of this bias under the plausible assumption that the revised data measure fundamentals with less error than the real-time data. Even under this upper bound, we can reject the hypothesis that our estimated responses are consistent with large effects of UI benefit extensions on unemployment.

Our discussion applies to observations at the state-month level, but we drop state-month subscripts to ease the notation. Let the observed duration of benefits, $T$, be equal to the sum of two orthogonal components:

$$
T=T^{F}+T^{E}
$$

where $T^{F}$ denotes the duration of benefits using the true unemployment rate and $T^{E}$ denotes the duration of benefits due to measurement error of the true unemployment rate. The true unemployment rate and $T^{F}$ are unknown to the econometrician. We allow $\tilde{T}$ to be an imperfect measure of the fundamentals:

$$
\tilde{T}=T^{F}+T^{X}
$$

where $T^{X}$ is the measurement error in the revised data.

The UI error that we defined in the main text, $\hat{T}$, can be written as:

$$
\hat{T}=T-\tilde{T}=T^{E}-T^{X} .
$$

In the presence of measurement error in the revised data, the UI error $\hat{T}$ is the difference between the measurement error in the true unemployment rate, $T^{E}$, and the measurement error in the 
revised data, $T^{X}$.

The three primitive objects of our analysis are $T^{F}, T^{E}$, and $T^{X}$. We write each variable $j=\{F, E, X\}$ as the sum of its expected value plus an innovation, $T^{j}=\mathbb{E} T^{j}+\epsilon^{j}$. All innovations $\epsilon^{j}$ 's are serially uncorrelated and uncorrelated with each other. The innovations in the measurement error components, $\epsilon^{E}$ and $\epsilon^{X}$, are uncorrelated with the fundamentals $F$. By contrast, the innovation $\epsilon^{F}$ is potentially correlated with the fundamentals $F$.

Taking expectations in equation (A.6) and using the definition of the innovations, we write the innovation in the real-time duration of benefits as:

$$
\epsilon^{T}=\epsilon^{F}+\epsilon^{E}
$$

Similarly, using equations (A.7) and (A.8), we write the innovation in the duration of UI benefits under the revised data and the innovation in the UI error (which we called $\epsilon$ in the main text) as:

$$
\begin{aligned}
& \epsilon^{\tilde{T}}=\epsilon^{F}+\epsilon^{X}, \\
& \epsilon^{\hat{T}}=\epsilon^{E}-\epsilon^{X} .
\end{aligned}
$$

Suppose the relationship between some outcome variable $y$ (that could be measured in a future period) and the innovation in the duration of benefits under the real-time data is:

$$
y=\beta \epsilon^{T}+\gamma F
$$

where $F$ collects all other factors that affect $y$. The fundamentals in $F$ are potentially correlated with $\epsilon^{T}$ through $\epsilon^{F}$ but are uncorrelated with the measurement error component $\epsilon^{E}$. Using equations (A.9) and (A.11) we can write:

$$
y=\beta \epsilon^{F}+\beta \epsilon^{X}+\beta \epsilon^{\hat{T}}+\gamma F
$$

The OLS coefficient in a regression of $y$ on $\epsilon^{\hat{T}}$ that omits $\epsilon^{F}$ and $\epsilon^{X}$ in the error term is given by:

$$
\beta^{\mathrm{OLS}}=\frac{\operatorname{Cov}\left(y, \epsilon^{\hat{T}}\right)}{\operatorname{Var}\left(\epsilon^{\hat{T}}\right)}=\frac{\operatorname{Cov}\left(\beta \epsilon^{X}+\beta \epsilon^{\hat{T}}, \epsilon^{\hat{T}}\right)}{\operatorname{Var}\left(\epsilon^{\hat{T}}\right)}=\beta\left(1-\frac{\operatorname{Var}\left(\epsilon^{X}\right)}{\operatorname{Var}\left(\epsilon^{\hat{T}}\right)}\right)
$$


where the second equality uses equation $(\mathrm{A} .13)$ and the fact that $\operatorname{Cov}\left(F, \epsilon^{\hat{T}}\right)=\operatorname{Cov}\left(\epsilon^{F}, \epsilon^{\hat{T}}\right)=$ 0 , and the third equality uses the fact that $\operatorname{Cov}\left(\epsilon^{X}, \epsilon^{\hat{T}}\right)=\operatorname{Cov}\left(\epsilon^{X}, \epsilon^{E}-\epsilon^{X}\right)=-\operatorname{Var}\left(\epsilon^{X}\right)$. If the revised data measure the true fundamentals without any error up to a constant, $\operatorname{Var}\left(\epsilon^{X}\right)=$ 0 , then the OLS estimator is unbiased $\beta^{\mathrm{OLS}}=\beta$. The attenuation bias is increasing in the variance of the measurement error in the revised data relative to the variance of the UI error, $\operatorname{Var}\left(\epsilon^{X}\right) / \operatorname{Var}\left(\epsilon^{\hat{T}}\right)$.

We now show that attenuation bias in our estimates is too small to affect our main conclusions under the plausible assumption that revised data do not deteriorate the quality of measurement of true fundamentals. We say that the revised data are a (weakly) better measure of the true fundamentals than the real-time data if the measurement error in the revised data has a (weakly) lower variance:

$$
\operatorname{Var}\left(\epsilon^{X}\right) \leq \operatorname{Var}\left(\epsilon^{E}\right)
$$

The assumption that the revised data contain less measurement error than the real-time data places an upper bound on the attenuation bias. From equation (A.11), we see that $\operatorname{Var}\left(\epsilon^{\hat{T}}\right)=$ $\operatorname{Var}\left(\epsilon^{X}\right)+\operatorname{Var}\left(\epsilon^{E}\right)$ and, therefore, under equation (A.15) less than 50 percent of the variance of $\epsilon^{\hat{T}}$ is attributed to $\epsilon^{X}$ :

$$
\frac{\operatorname{Var}\left(\epsilon^{X}\right)}{\operatorname{Var}\left(\epsilon^{\hat{T}}\right)} \leq 0.5 .
$$

We estimate in the data an upper bound of $\beta^{\mathrm{OLS}}=0.02$. Using the upper bound of the bias $\operatorname{Var}\left(\epsilon^{X}\right) / \operatorname{Var}\left(\epsilon^{\tilde{T}}\right)=0.50$, the true coefficient could be as large as $\beta=0.04$. Using a standard error of 0.02 , this $\beta$ is still 4.5 standard errors below the 0.15 level that would rationalize a large effect of extended benefits on unemployment during the Great Recession.

This calculation is very conservative because it assumes that revisions do not improve measurement and uses the upper bound of our estimates of $\beta$. In Section 3.4 we provided evidence that revisions are informative about actual spending patterns and beliefs. This implies that $\operatorname{Var}\left(\epsilon^{X}\right) / \operatorname{Var}\left(\epsilon^{\tilde{T}}\right)$ is likely to be smaller than 0.5. Indeed, we find in the data that there is smaller variance of outcomes in the revised data and, consistent with our as- 
sumption that $\operatorname{Var}\left(\epsilon^{X}\right) \leq \operatorname{Var}\left(\epsilon^{E}\right)$, that $\operatorname{Var}\left(\epsilon^{\tilde{T}}\right)<\operatorname{Var}\left(\epsilon^{T}\right)$. If we apply, for example,

$\operatorname{Var}\left(\epsilon^{X}\right) / \operatorname{Var}\left(\epsilon^{\tilde{T}}\right)=0.25$ to our maximum estimate of $\beta^{\text {OLS }}=0.02$, we obtain that the true coefficient is $\beta<0.03$. More in general, the more informative is the revised data for the true fundamentals, the lower is $\operatorname{Var}\left(\epsilon^{X}\right) / \operatorname{Var}\left(\epsilon^{\tilde{T}}\right)$ and the smaller is the attenuation bias.

\section{Model Appendix}

In this appendix we present additional results from the model. In Figures A.1, A.2, and A.3, we present the impulses of the fraction of unemployed receiving UI, the log opportunity cost, and $\log$ vacancies to a one-month increase in the UI error innovation. In Figures A.4 and A.5 we depict the path of productivity and separations shocks underlying the experiment depicted in Figure 8 in the main text. In each figure, the left panel corresponds to the high $b$ model and the right panel corresponds to the low $b$ model.

In Figure A.6 we illustrate the Regression Discontinuity (RD) framework using modelgenerated data. The point we wish to make is that, under very persistent shocks, a pure RD framework is not able to detect significant effects of UI benefit extensions on macroeconomic outcomes despite the existence of such effects. For this figure, we continue to use the same parameters as in the high $b$ model of Table 10 except that we increase the persistence of log productivity to $\rho=0.98$. We also adjust the volatility of the productivity shocks to $\sigma=0.004$ so that the model generates the same volatility of log productivity as the baseline high $b$ model in the main text. We then simulate the model for a large number of periods.

The right panel of Figure A.6 shows the relationship between $u_{t+1}$ in the vertical axis and $u_{t}$ in the horizontal axis generated by the model. The left panel of the figure shows the relationship between $u_{t+2}$ and $u_{t}$. The plotted lines denote third-order polynomials fitted on model-generated data left and right of the cutoffs denoted with vertical lines. As we see in the figure, there is no significant discontinuity around the points in which the duration of benefits increases sharply. When shocks are very persistent, forward-looking agents in an economy that starts just below the cutoff expect benefit extensions in the future. Therefore, equilibrium outcomes are not 


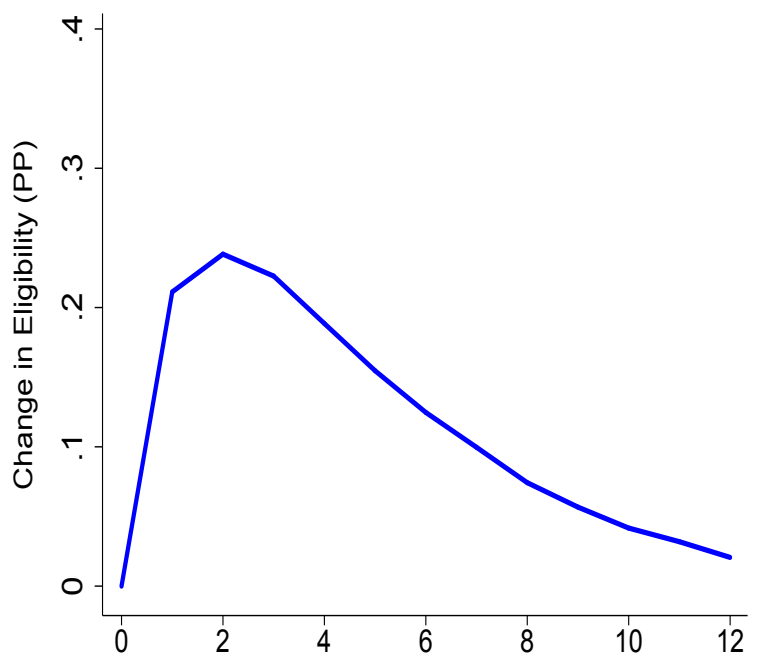

(a) High $b$ Model

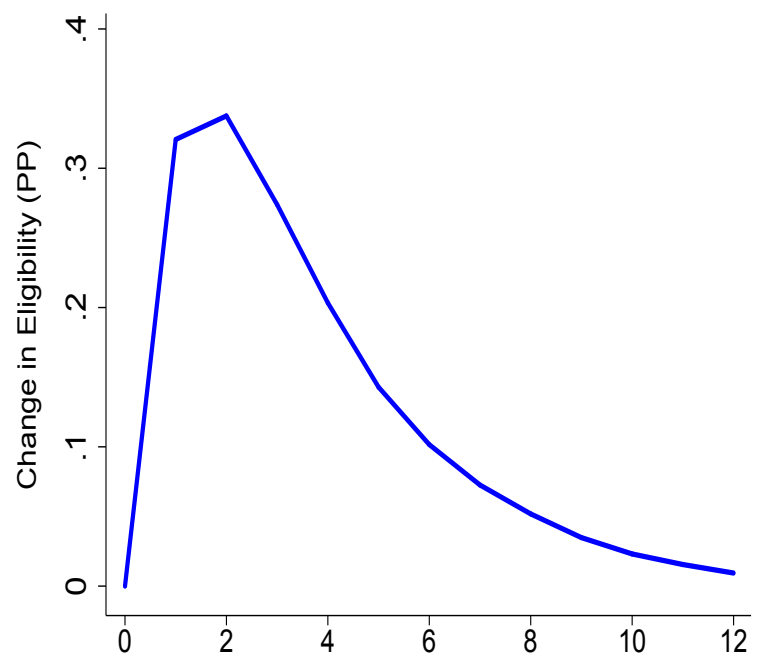

(b) Low $b$ Model

Figure A.1: Impulse Response of Fraction Receiving UI in the Model

Notes: The figure plots the coefficients on $\epsilon_{t}$ from the regression $\omega_{t+h}=\beta(h) \epsilon_{t}+\nu_{t+h}$ using data generated from model simulations.

significantly different relative to the outcomes observed in an economy that starts just above the cutoff.

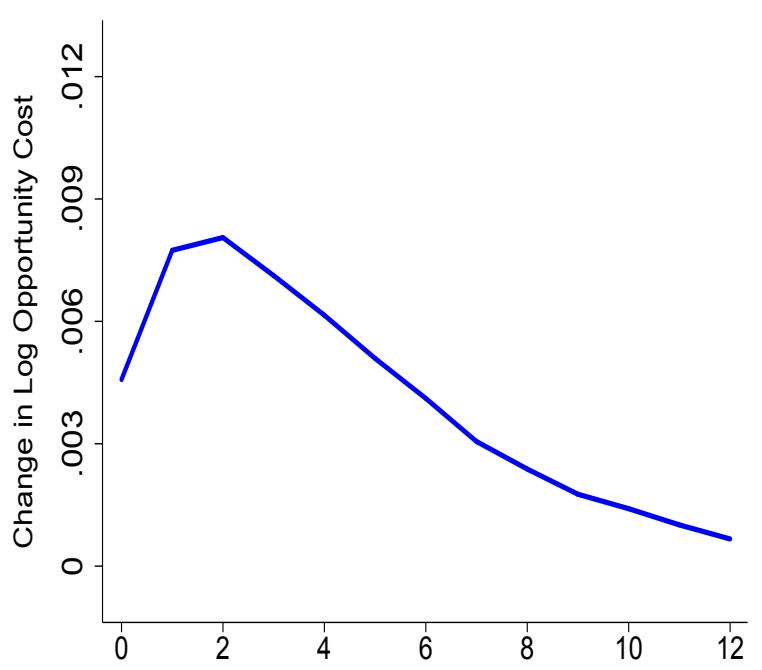

(a) High $b$ Model

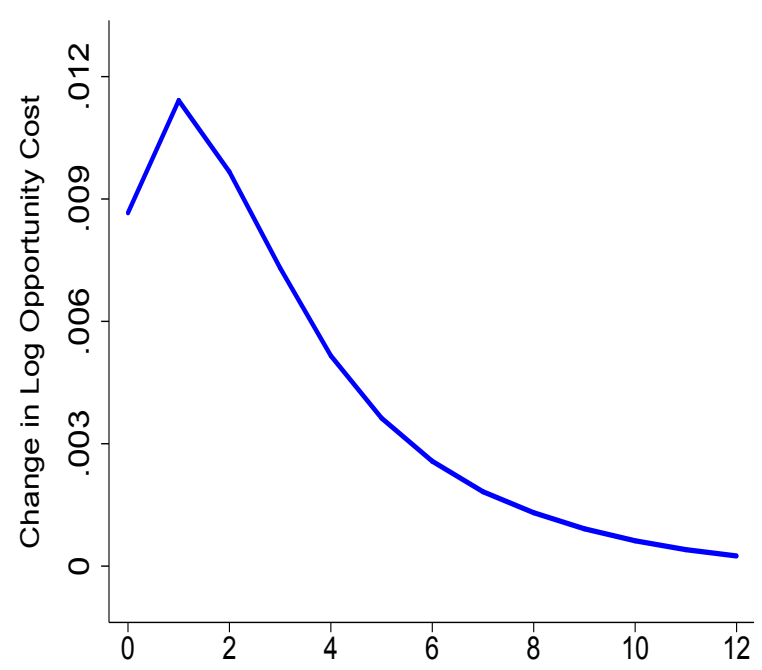

(b) Low $b$ Model

Figure A.2: Impulse Response of Log Opportunity Cost in the Model

Notes: The figure plots the coefficients on $\epsilon_{t}$ from the regression $\log b_{t+h}=\beta(h) \epsilon_{t}+\nu_{t+h}$ using data generated from model simulations. 


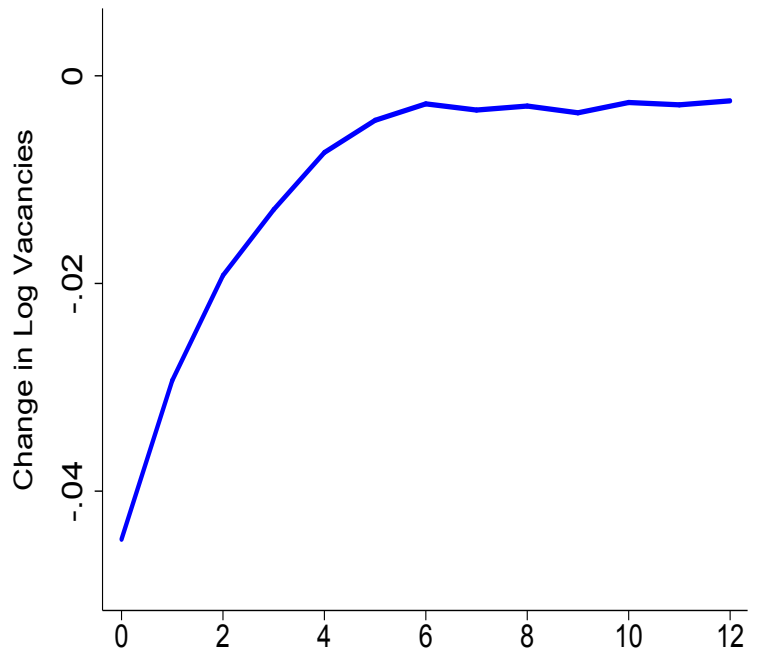

(a) High $b$ Model

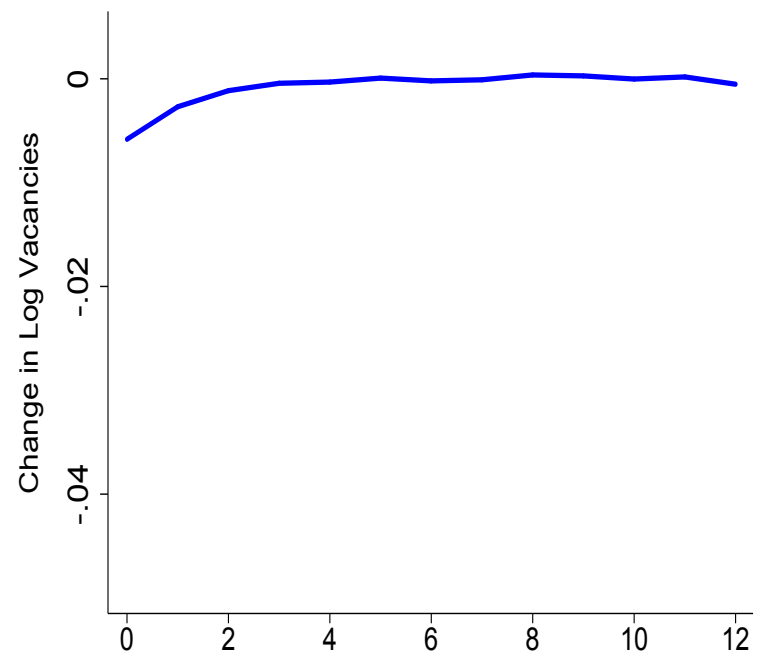

(b) Low $b$ Model

Figure A.3: Impulse Response of Log Vacancies in the Model

Notes: The figure plots the coefficients on $\epsilon_{t}$ from the regression $\log v_{t+h}=\beta(h) \epsilon_{t}+\nu_{t+h}$ using data generated from model simulations.

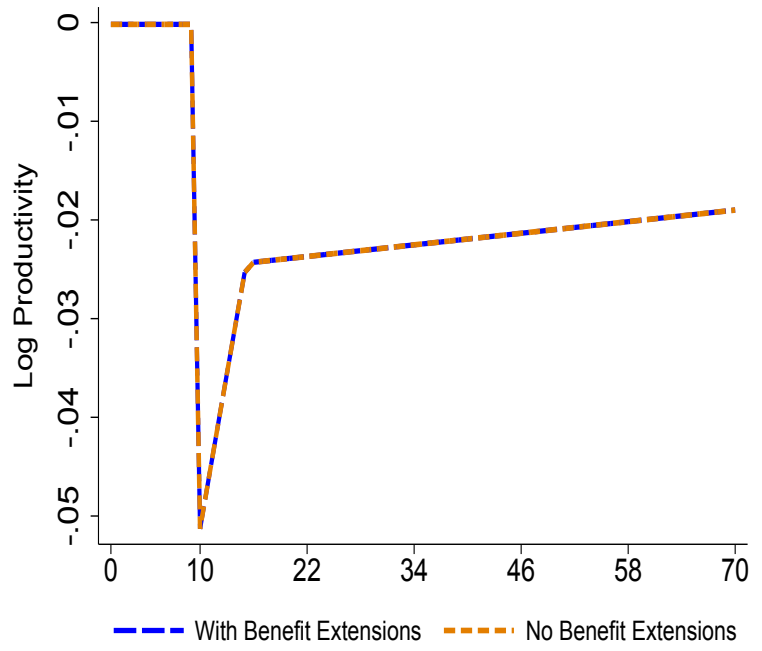

(a) High $b$ Model

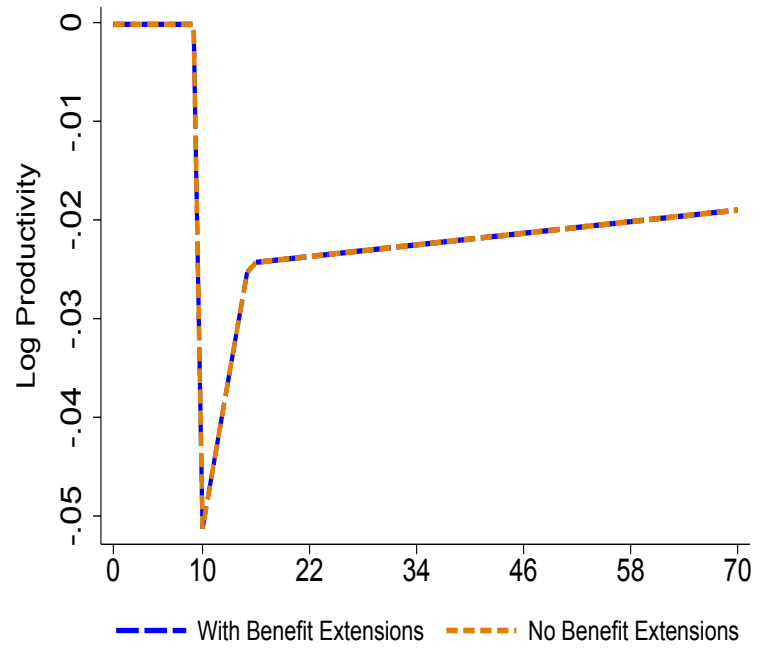

(b) Low $b$ Model

Figure A.4: Productivity Path in the Model

Notes: The figure plots the path of productivity used to generate the simulation in Figure 8. 


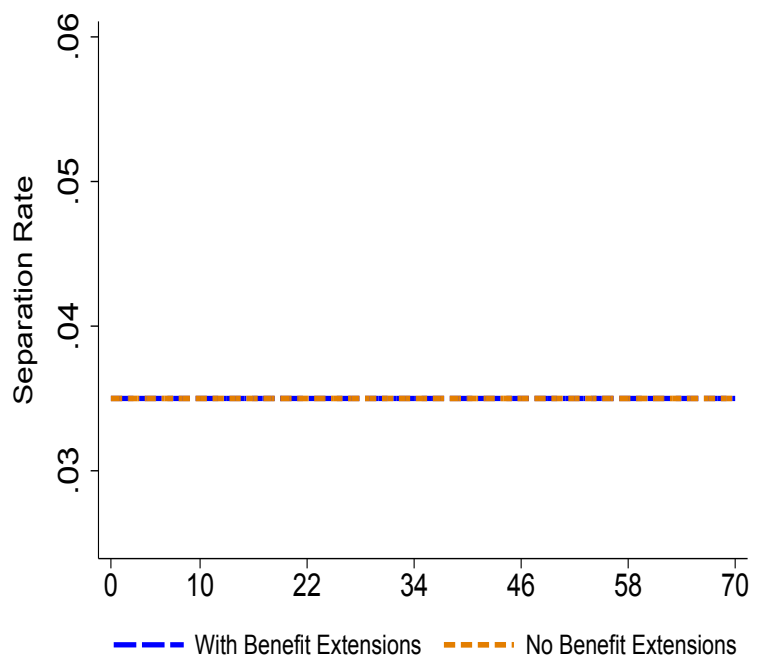

(a) High $b$ Model

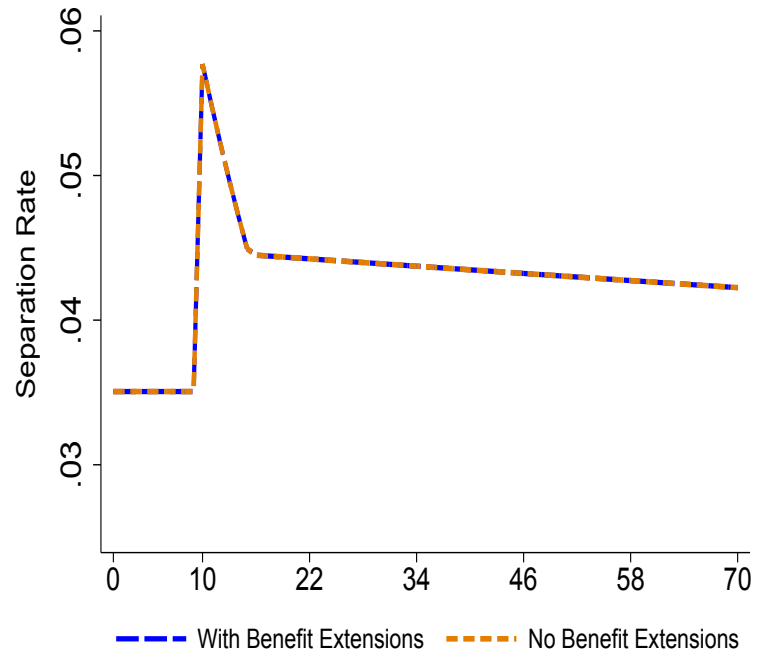

(b) Low $b$ Model

Figure A.5: Separations in the Model

Notes: The figure plots the path of the separation rate used to generate the simulation in Figure 8.

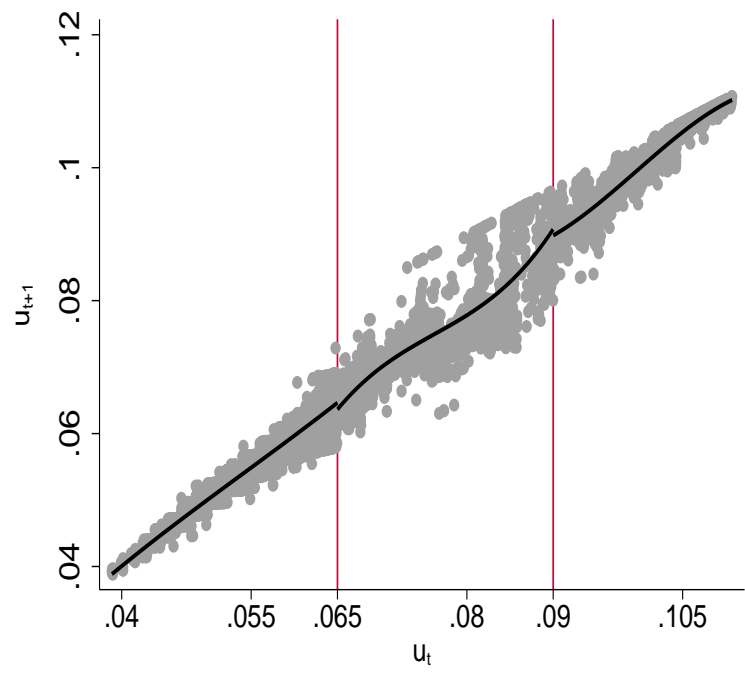

(a) Unemployment Rate in $t+1$

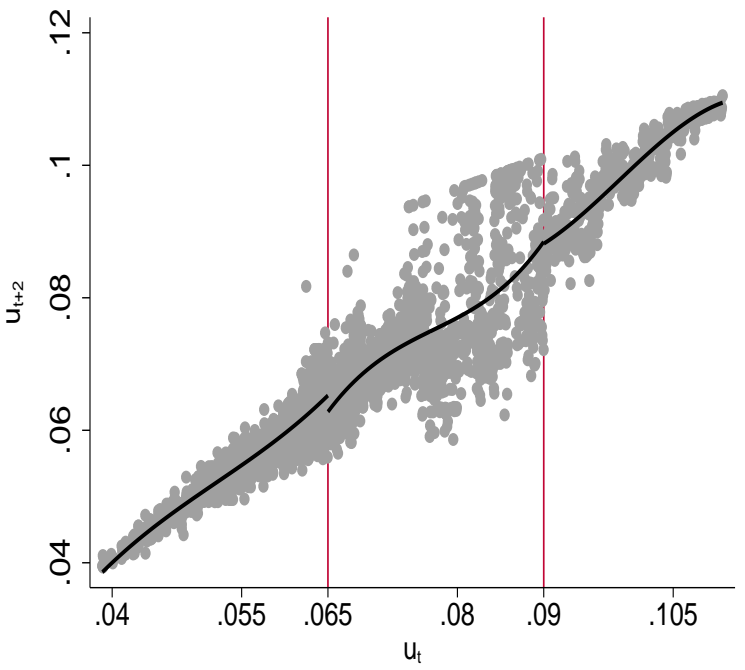

(b) Unemployment Rate in $t+2$

Figure A.6: Regression Discontinuity in Model-Generated Data

Notes: The figure plots the relationship between $u_{t}$ and $u_{t+1}$ (left panel) and $u_{t+2}$ (right panel) generated from simulated data. 


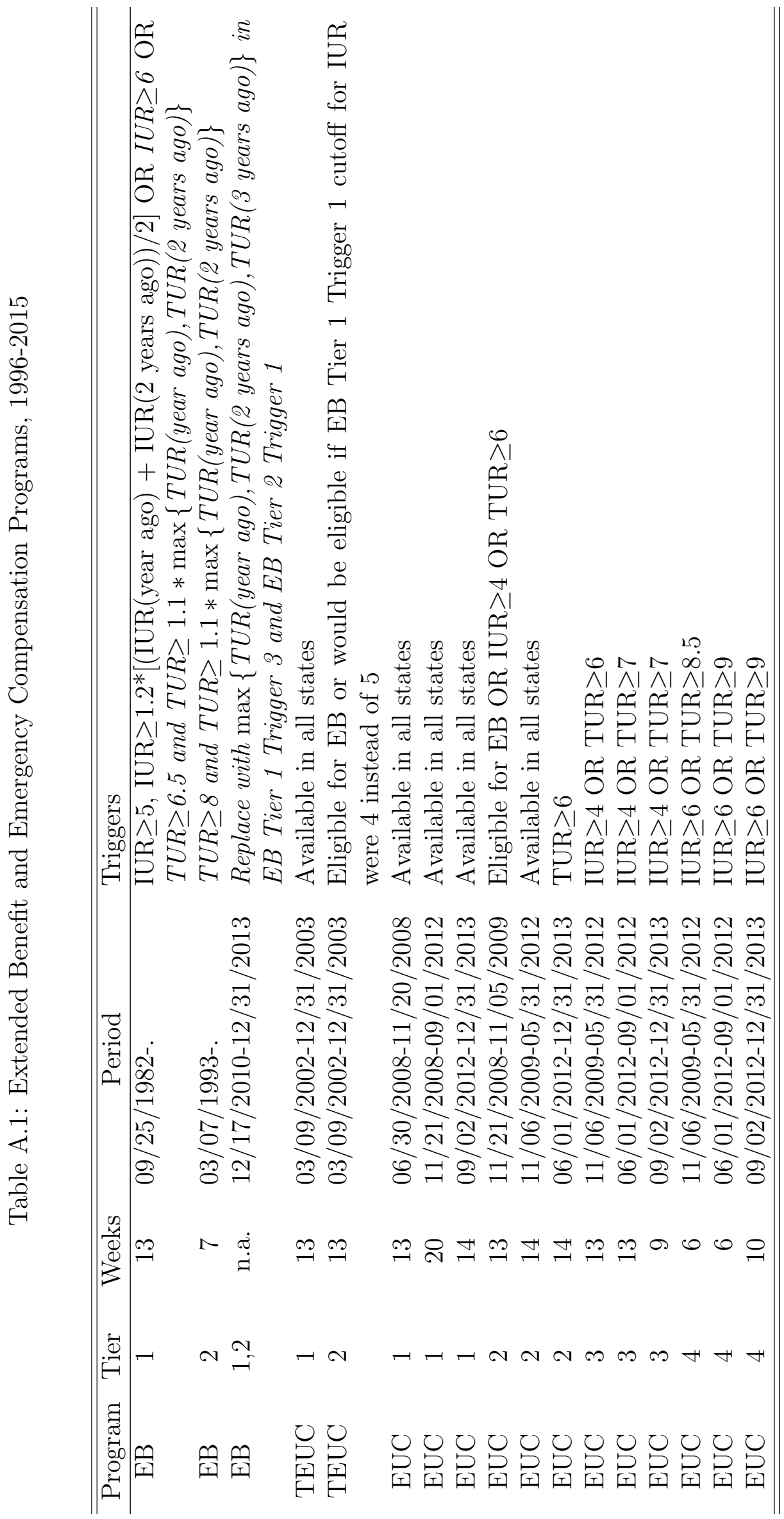

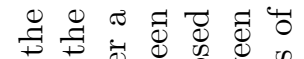

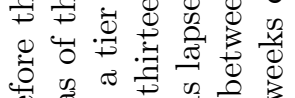

¿ 0 व

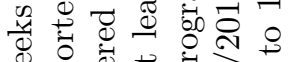

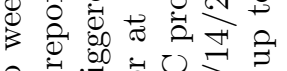

ॐ.

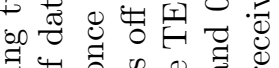

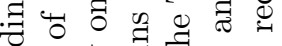

혁 공

जิ

ष्व

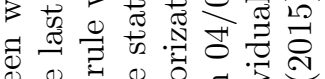
\&

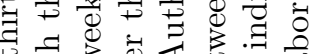

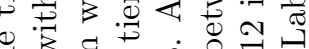

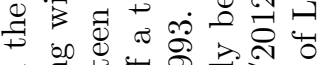

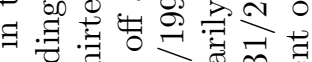

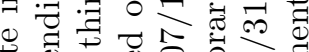

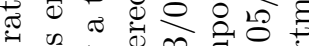
पद 苛 है

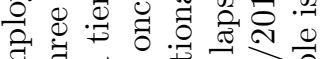
द्व $\exists$ च

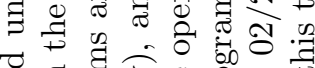
¿. ज.

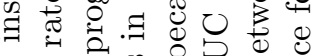

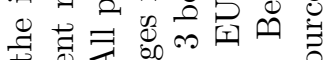
प

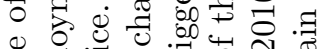
80.

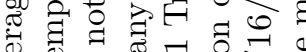

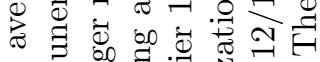
포욜 .

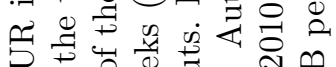

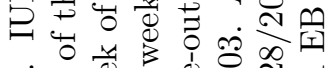

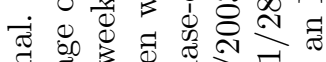

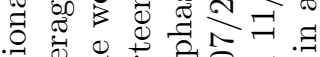

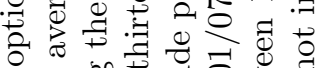
0 क

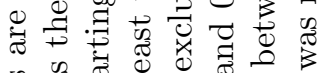

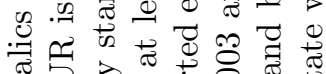
西? 层苛

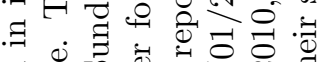

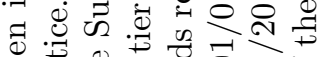

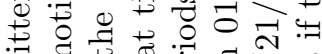

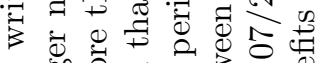
我. .0 D.

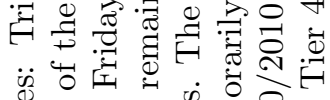

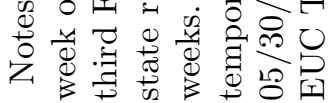

